\title{
S100A16 Promotes Acute Kidney Injury By Activating HRD1-Induced Ubiquitination And Degradation of GSK3 $\beta$ And CK1a
}

\section{Yifei Sun}

Nanjing Medical University

\section{Ya Fan}

Nanjing Medical University

Min Li

Nanjing Medical University

\section{Zheng Wang}

Nanjing Medical University

Dongming Su

Nanjing Medical University

Yun Liu

Nanjing Medical University

Xiubin Liang ( $\boldsymbol{\nabla}$ liangxiubin@njmu.edu.cn )

Nanjing Medical University https://orcid.org/0000-0001-9169-0390

\section{Research Article}

Keywords: S100A16, acute kidney injury, Wnt/ß-catenin, ischemia-reperfusion injury, renal interstitial fibroblasts

Posted Date: September 7th, 2021

DOI: https://doi.org/10.21203/rs.3.rs-835880/v1

License: (a) (i) This work is licensed under a Creative Commons Attribution 4.0 International License. Read Full License

Version of Record: A version of this preprint was published at Cellular and Molecular Life Sciences on March 1st, 2022. See the published version at https://doi.org/10.1007/s00018-022-04213-5. 


\section{Abstract}

The pathogenesis of acute kidney injury (AKI) is associated with activation of multiple signaling pathways, including Wnt/ $\beta$-catenin signaling. However, the mechanism of Wnt/ $\beta$-catenin pathway activation in renal interstitial fibroblasts during AKI is unclear. S100 calcium binding protein A16 (S100A16), a new member of calcium binding protein $\mathrm{S} 100$ family, is a multi-functional signaling factor involved in various pathogenies, including tumors, glycolipid metabolism disorder, and chronic kidney disease (CKD). We investigated the potential participation of S100A16 in Wnt/ $\beta$-catenin pathway activation during AKI by subjecting wild-type (WT) and S100A16 knockout (S100A16 $\left.{ }^{+/-}\right)$mice to the ischemia-reperfusion injury (IRI), and revealed S100A16 upregulation in this model, in which knockout of S100A16 impeded the Wnt/ $\beta$-catenin signaling pathway activation and recovered the expression of downstream hepatocyte growth factor (HGF). We also found that S100A16 was highly expressed in a-

SMA positive renal fibroblasts in vivo. Consistently, in rat renal interstitial fibroblasts (NRK-49F cells), both hypoxia and S100A16 overexpression exacerbated fibroblasts apoptosis and inhibited HGF secretion; whereas S100A16 knockdown or Wnt/ $\beta$-catenin pathway inhibitor ICG-001 reversed these changes. Mechanistically, we show that S100A16 promotes Wnt/ $\beta$-catenin signaling activation via the ubiquitylation and degradation of $\beta$-catenin complex members, glycogen synthase kinase $3 \beta$ (GSK3 $\beta$ ) and casein kinase $1 \mathrm{a}(\mathrm{CK} 1 \mathrm{a})$, mediated by E3 ubiquitin ligase, the HMG-CoA reductase degradation protein 1 (HRD1). Our study identified the S100A16 as a key regulator in the activation of Wnt/ $\beta$-catenin signaling pathway in AKI.

\section{Introduction}

AKI is associated with high morbidity and mortality, claiming about 1.7 million lives worldwide each year [1]. AKI is clinically considered a rapid decline in renal function from a variety of causes, of which IRI is widely considered the most important cause [2]. Initially considered a self-healing disease, recent studies have shown that severe AKI leads to incomplete renal repair, persistent chronic inflammation, and fibrosis progression, and eventually chronic organ loss [3, 4]. The long-term consequences of AKI include CKD and even serious end-stage renal disease (ESRD), both associated with a poor quality of life and high cost of care, thereby imposing a significant burden on the society $[5,6]$. Therefore, understanding the pathogenesis of $\mathrm{AKI}$, and developing prevention and treatment strategies are of the great significance for prolonging the lifespan of patients and reducing the societal burden.

Multiple signaling pathways contribute to the pathogenesis of AKI. In particular, the activation of Wnt/ $\beta$ catenin pathway plays an irreplaceable role in severe AKI. Wnt/ $\beta$-catenin signaling is an evolutionarily conserved developmental signaling pathway that is involved in organogenesis, tissue balance, and disease progression [7, 8]. In adult kidneys, Wnt signaling is usually silent $[9,10]$. However, when the kidney is subjected to IRI, Wnt/ $\beta$-catenin signaling is activated in the cells of kidney $[11,12]$.

In the canonical Wnt/ $\beta$-catenin signaling pathway, the transcriptional coactivator $\beta$-catenin is regulated by the $\beta$-catenin degradation complex, which consists of GSK3 $\beta$, CK1a, adenomatous polyposis E. coli 
(APC), and scaffold protein (Axin) [13]. In the absence of Wnt (Wnt-off), $\beta$-catenin is phosphorylated by the $\beta$-catenin degradation complex GSK3 $\beta$. Phosphorylated $\beta$-catenin is recognized for proteasome degradation by the E3 ubiquitin ligase $\beta$-Trcp, and the loss of $\beta$-catenin subsequently inhibits the transcription of Wnt target genes in the nucleus. However, when the kidney is severely damaged, the Wnt ligands bind to the transmembrane frizzled protein receptor (FZD) and to the low-density lipoprotein receptor-related protein 5 or 6 (LRP5/6) in the Wnt-on (containing Wnt) state. These events lead to the destruction of the $\beta$-catenin degradation complex, thereby impairing the degradation of $\beta$-catenin in the cytoplasm. Subsequently, the stable and accumulated $\beta$-catenin is transferred to the nucleus, where it stimulates transcription of downstream target genes $[14,15]$.

Recent studies have demonstrated that renal interstitial fibroblasts play an important role in the activation of Wnt/ $\beta$-catenin signaling in short-term IRI induction (24 hours after IRI surgery). Renal interstitial fibroblasts can secrete a range of growth factors, including HGF, to regulate kidney growth and repair the damage kidney. HGF is a pleiotropic growth factor that plays a vital role in the repair of renal tubular injury $[16,17]$. Activation of the Wnt/ $\beta$-catenin signaling pathway in renal interstitial fibroblasts inhibits downstream HGF/c-met signaling, thereby inhibiting the repair of renal tubules damage by IRI [18]. However, the mechanism of Wnt/ $\beta$-catenin signaling pathway activation in renal interstitial fibroblasts during AKI are still unclear.

One potential activator is S100A16, a newly identified member of the calmodulin S100 family. S100A16 is a small molecule acidic $\mathrm{Ca}^{2+}$-binding protein that has received attention because of its unique characteristics that differ from those of other members of the $S 100$ family $[19,20]$. Previous studies have shown that the members of the $\mathrm{S} 100$ protein family are regarded as multi-function signal factors involved in various processes of intracellular or extracellular regulation. Functionally, the S100 protein family can regulate cell proliferation, differentiation, migration, apoptosis, and autoimmunity [21, 22]. S100A16, in particular, is widely expressed in human tissues and is a highly conserved protein in mammals $[23,24]$. It is revealed as a novel lipogenic factor that promotes the formation of lipid droplets during the differentiation of 3T3-L1 cells. S100A16 also negatively regulates insulin sensitivity in 3T3-L1 cells. These results have suggested that S100A16 is closely associated with obesity [25]. In our previous study, we reported that the protein expression of S100A16 is significantly increased in the kidney of unilateral ureteral occlusion (UUO) mice and the characteristic pathological changes of renal tubulointerstitial fibrosis appeared in the kidney of S100A16 transgenic mice, indicating a positive relationship between S100A16 and tubulointerstitial fibrosis. Moreover, S100A16 is also highly expressed in kidney biopsy specimens from patients with various clinical nephropathy [26].

In the present study, we investigated the biological function and molecular mechanism of S100A16 in AKI using an S100A16 knockout mouse model and renal interstitial fibroblasts (NRK-49F cells).

\section{Results}




\section{S100A16 knockout attenuates kidney injury in mouse AKI model}

We investigated the pathogenic relevance of S100A16 in AKI by first examining the S100A16 protein expression in the kidney tissues in WT mice and S100A16 ${ }^{+/-}$mice with or without an IRI procedure. Of note, S100A16 homozygous knockout is embryonic lethal. As shown in Fig. 1a, S100A16 expression was strongly increased in the kidney of IRI WT mice than in the sham groups. Interestingly, although of the same direction, IRI had less effect on S100A16 expression in S100A16 ${ }^{+/-}$group. The quantified data are shown in Fig. 1b. Further assessment of S100A16 expression by immunohistochemistry staining $(\mathrm{IHC})$ in kidney samples revealed a strong upregulation of S100A16 expression in the renal interstitium of WT IRI mice, but only a mild change in kidneys of the S100A16 ${ }^{+/-}$IRI animals (Fig. 1C). These results were consistent with the biochemistry data.

We then examined the histological changes in WT and S100A $16^{+/-}$mouse kidneys with or without the IRI procedure. Renal tissues stained with hematoxylin-eosin (HE) showed tubular dilatation in WT mice after IRI, while periodic acid-Schiff (PAS) staining showed expansion of the inner edges of the renal tubules, rupture of the renal tubular basement membranes, and appearance of protein casts and cell debris in the lumen after renal IRI. By contrast, the S100A16 ${ }^{+/-}$mice showed a marked reduction in the pathology of renal injury induced by IRI (Fig. 1d). As shown in Fig. 1e and Fig. 1f, tests of serum creatinine (Scr) and blood urea nitrogen (BUN) conducted $24 \mathrm{~h}$ after IRI showed significant elevation in WT mice after IRI compared to the sham group. However, the S100A16 ${ }^{+/-}$IRI mice had markedly lower levels of Scr and BUN compared with WT IRI mice. Western blot analyses also revealed that S100A16 heterozygous knockout effectively inhibited the IRI-induced upregulation of pro-apoptotic genes including BAX, Cleaved Caspase3, and Caspase3, and reversed the destruction of HGF, the renal repair cytokine (Fig. 1a and 1b). These data indicated that S100A16 knockout has a protective role in renal IRI, likely through attenuating the degree of renal ischemia and hypoxia injury.

\section{S100A16 knockout reduced activation of Wnt/ $\beta$-catenin pathway in AKI mice}

HGF is a downstream factor of Wnt/ $\beta$-catenin signaling pathway. S100A16 knockout increased HGF expression as shown in Fig. 1a. Therefore, we further explored whether S100A16 is involved in the activation of the Wnt/ $\beta$-catenin signaling pathway induced by renal IRI. As shown in Fig. 2a, the expressions of Active $\beta$-catenin (non-phospho $\beta$-catenin at Ser33/37/Thr41) and Total $\beta$-catenin were significantly upregulated in WT mice at $24 \mathrm{~h}$ after the IRI procedure compared to the corresponding sham groups. This finding indicated that the Wnt/ $\beta$-catenin signaling pathway is activated by IRI in this mouse model. However, the expressions of $\beta$-catenin-driven genes after IRI were significantly lower in the S100A $16^{+/-}$kidney than in WT injured kidney. Together, these data indicated that S100A16 knockout diminished the IRI-induced activation of Wnt/ $\beta$-catenin pathway. The quantified data for Active $\beta$-catenin and Total $\beta$-catenin expression are shown in Fig. $2 \mathrm{~b}$. 
We then interrogated the relationship between Wnt signals and S100A16. Real-time PCR analyses showed a sustained activation of numerous Wnt ligands, including Wnt2, Wnt3, Wnt4, Wnt7a, Wnt7b, Wnt8a, Wnt10b, and Wnt16, at $24 \mathrm{~h}$ after the IRI treatment in WT mice compared to WT sham mice (Fig. S1). By contrast, the mRNA levels of Wnt ligands were close to the sham WT baseline in the S100A16 ${ }^{+/-}$ IRI mice (Fig. S1). These results confirmed that S100A16 positively regulates the activation of the Wnt/ $\beta$ catenin signaling pathway in the kidney after IRI. The IHC staining data of $\beta$-catenin confirmed Wnt $/ \beta$ catenin activation after IRI in WT mice, but not in S100A16 $6^{+/-}$mice (Fig. 2c).

\section{S100A16 directly participates in hypoxia-induced Wnt/ $\beta$ - catenin signaling activation in renal fibroblasts}

To identify the localization of S100A16 in vivo, we performed the double immunofluorescence staining for S100A16 and a-smooth muscle actin (a-SMA) in AKI kidney tissues. The data revealed that S100A16 was highly expressed in a-SMA positive renal fibroblasts (Fig. S2). To further investigate the role of S100A16 in AKI linked to Wnt/ $\beta$-catenin signaling, rat renal interstitial fibroblasts (NRK-49F cells) were cultured under basal or hypoxic conditions, with or without different concentrations $(0,5$, and $10 \mu \mathrm{M})$ of ICG-001, a Wnt/ $\beta$-catenin signaling pathway inhibitor. Cell lysates from NRK-49F cells were tested by western blotting for protein expressions of $\beta$-catenin-driven genes and cell injury related genes. As shown in Fig. 3a, exposure of NRK-49F cells to hypoxia triggered increased expressions of Active $\beta$-catenin and Total $\beta$-catenin, and markedly evoked the expressions of BAX, Cleaved Caspase 3 and Caspase3.

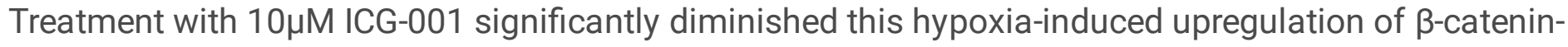
driven genes and pro-apoptotic genes in NRK-49F cells. In contrast, the protein expression of HGF, a downstream target of Wnt/ $\beta$-catenin pathway, was restored by ICG-001 treatment in NRK-49F cells under hypoxia conditions. These results indicated that injury induced in renal interstitial fibroblasts by hypoxia facilitates the activation of Wnt/ $\beta$-catenin signaling pathway and inhibits downstream HGF expression. Quantitative results are shown in Fig. $3 b$.

We then used S100A16 knockdown and S100A16 overexpressing in NRK-49F cells to further investigate the role of S100A16 in renal hypoxia injury. We knocked down S100A16 expression in NRK-49F cells using shRNA and used scrambled shRNA as control. As shown in Fig. 3c, knockdown of S100A16 in NRK49 cells reduced the protein expressions of Active $\beta$-catenin and Total $\beta$-catenin induced by hypoxia. Western blots also revealed the increased protein expressions of apoptosis-related genes and the decreased protein expression of HGF caused by hypoxia were effectively reversed by S100A16 knockdown. Quantitative results are shown in Fig. 3d.

Overexpression of S100A16, on the other hand, upregulated the protein expressions of Active $\beta$-catenin and Total $\beta$-catenin along with apoptosis-related genes, and this upregulation was inhibited by ICG-001. Notably, the protein expression of HGF was markedly reduced by S100A16 overexpression, which is also

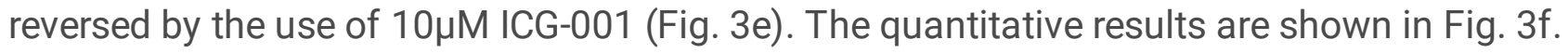

\section{S100A16 regulates HRD1 during Wnt/ $\beta$-catenin pathway activation}


In our previous study, we had identified that CK1a, a $\beta$-catenin degraded complex member, is a substrate for HRD1, an E3 ubiquitin ligase [27]. In the present study, we examined whether HRD1 is associated with S100A16 in the process of Wnt/ $\beta$-catenin pathway activation.

IHC staining showed a marked increase in the expression of HRD1 in the WT kidney tissues following IRI, but not in the S100A16 $6^{+/-}$ones (Fig. 4a). These differences in HRD1 expression were confirmed by western blot (Fig. 4b), and by real-time PCR (Fig. S3a). The GSK3 $\beta$ and CK1a in the kidney lysates were lower after IRI than those before IRI in WT groups, whereas in the S100A16 ${ }^{+/-}$kidney lysates, the protein expressions of GSK3 $\beta$ and CK1a were restored to 95\% compared with WT kidney (Fig. 4b). Quantitative results of the expressions of HRD1, GSK3 $\beta$ and CK1a are shown in Fig. 4c. These results indicated that IRI induces increased HRD1 protein expression and decreased the protein expressions of GSK3 $\beta$ and CK1a in mice, and that S100A16 knockout eliminated these changes.

We then explored the potential involvement of HRD1 in the activation of Wnt/ $\beta$-catenin pathway during renal ischemia and hypoxia, by pretreating NRK-49F cells under the hypoxia condition with different regulation of S100A16. We found that HRD1 expression was increased under hypoxic stimulation and was attenuated by ICG-001 (Fig. 4d and 4e). Hypoxia also increased the mRNA level of HRD1, as detected by real-time PCR (Fig. S3b). We then transfected S100A16 shRNA into NRK-49F cells to knock down S100A16 expression. HRD1 expression was decreased in NRK-49F cells transfected with S100A16 shRNA compared to the normal control or scrambled shRNA control, and S100A16 knockdown also impeded the hypoxia-induced upregulation of HRD1. By contrast, the changes in the protein expression levels of GSK3 $\beta$ and CK1 a were opposite to those of HRD1 (Fig. $4 \mathrm{f}$ and $4 \mathrm{~g}$ ). We also observed that the protein expression of HRD1 was augmented when S100A16 was overexpressed in NRK-49F cells, and that is augmentation was reversed by treatment with $10 \mu \mathrm{M}$ ICG-001. The protein expression changes in GSK3 $\beta$ and CK1a were opposite to those of HRD1 (Fig. 4h and 4i). These data suggested that S100A16 potentiates the activation of Wnt/ $\beta$-catenin signaling pathway by upregulating HRD1.

\section{HRD1 physically binds and promotes the ubiquitination and degradation of GSK3 $\beta$ and CK1a}

We then conducted co-IP experiments to examine the interaction between HRD1 and GSK3 $\beta$, as well as the interaction between HRD1 and CK1a, in NRK-49F cells using antibodies against GSK3 $\beta$ and CK1a, respectively, to isolate proteins from NRK-49F cells. The isolated proteins were then examined by western blotting to detect binding signals of HRD1. IgG was used as a control which yielded no HRD1 positive signal in immunoprecipitations (IPs). The binding signals of GSK3 $\beta$ and CK1a with HRD1 were detected by anti-HRD1 antibody in IPs, and subsequently blotting with GSK3 $\beta$ and CK1a antibody. As shown in Fig. $5 a$, we detected physical HRD1 bindings with GSK3 $\beta$ and CK1a in NRK-49F cell lysates. Double immunofluorescence staining confirmed that HRD1 colocalized with GSK3 $\beta$ and CK1a in the cytoplasm of NRK-49F cells (Fig. S4a and S4b), in agreement with the co-IP analysis. 
We also explored the effect of HRD1 on the stability of GSK3 $\beta$ and CK1a expression by performing a cycloheximide (CHX, a protein translation inhibitor) chase assay. Adenovirus HRD1 (Ad-HRD1) was transfected into NRK-49F cells, and the cells were treated with $\mathrm{CHX} 48 \mathrm{~h}$ later, for 0, 2, 4 or 6 hours to block the synthesis of new polypeptides. As shown in Fig. $5 b$ and $5 c$, the rate of protein disappearance of both GSK3 $\beta$ and CK1a was more rapid in the Ad-HRD1 transfected cells than in the control group, indicating that HRD1 is involved in promoting protein degradation of GSK3 $\beta$ and CK1a. Therefore, overexpressed HRD1 in NRK-49F cells resulted in shorter half-lives for both GSK3 $\beta$ and CK1a protein expressions.

As shown in Fig. 5d and 5e, treatment with MG132, a proteasome inhibitor, increased the protein expressions of endogenous GSK3 $\beta$ and CK1 a compared to each corresponding control group, but AdHRD1 did not affect mRNA level of either GSK3 $\beta$ or CK1a (Fig. S5a and S5b). These results implied that HRD1 degrades GSK3 $\beta$ and CK1a via the ubiquitin-proteasome degradation pathway. We verified this by transfecting ubiquitin (Ub) plasmids into NRK-49F cells with or without Ad-HRD1 infection. GSK3 $\beta$ and CK1a were separately immunoprecipitated and the protein expression of ubiquitin was observed by western blotting. We detected a higher protein expression of ubiquitin in the cells infected with Ad-HRD1 than in the cells without Ad-HRD1 infection (Fig. 5f-5i). These findings verified that HRD1 promotes the ubiquitination of GSK3 $\beta$ and CK1a in NRK-49F cells.

\section{S100A16 participates in AKI by mediating the downregulation of GSK3 $\beta$ and CK1 $a$ through HRD1 in renal fibroblasts}

We explored the possible molecular mechanism of S100A16 in AKI via HRD1-mediated Wnt/ $\beta$-catenin pathway activation by co-transfecting Ad-HRD1 and S100A16 overexpressing (OE) plasmids into NRK$49 \mathrm{~F}$ cells to detect the protein expressions of GSK3 $\beta, \mathrm{CK} 1 \mathrm{a}$, and HGF. These results showed markedly decreased protein expression levels of GSK3 $\beta$, CK1a and HGF in NRK-49F cells co-transfected with AdHRD1 and S100A16 OE plasmids compared to control groups (Fig. 6a and 6b). The mRNA levels of HGF, determined by real-time PCR, were consistent with protein expression values, as shown in Fig. 6c. The degradation of GSK3 $\beta$ and CK1a by Ad-HRD1 in NRK-49F cells was suppressed by transfection with S100A16 shRNA compared with cells transfected scrambled shRNA. The S100A16 shRNA restored HRD1mediated downstream HGF suppression, as shown in Fig. 6d and 6e. These data demonstrated that S100A16 participates in AKI by promoting HRD1-mediated degradation of GSK3 $\beta$ and CK1a.

The immunofluorescence staining of $\beta$-catenin confirmed that $\beta$-catenin was mainly expressed in the cytoplasm of NRK-49F cells transfected with vector only, but positive signals of $\beta$-catenin were evident in the nucleus of NRK-49F cells infected with Ad-HRD1, and these signals were even stronger in the nucleus of cells infected with the Ad-HRD1 and S100A16 OE combination (Fig. 6f).

\section{Discussion}


The pathogenesis of AKI is a complex process. AKI is a complication with high clinical incidence and mortality and is often caused by special factors, such as hypotension, bacterial infection, sepsis, and toxic invasion, that lead to microcirculation damage, inflammation, and renal tubular injury [28]. IRI is the main culprit in AKI. The oxygen supply to the kidney is extremely rich, so the kidney is one of the organs most vulnerable to oxygen free radical damage in the body and is highly sensitive to IRI [29]. The pathophysiological process of IRI is complicated and involves energy depletion due to hypoxia as well as inflammatory response, oxidative stress and apoptosis. The prevention and treatment of IRI are therefore of great significance to AKI patients [30].

Previous studies have suggested that the role of the Wnt/ $\beta$-catenin signaling pathway in AKI is a doubleedged sword: activation of the transient Wnt/ $\beta$-catenin signaling pathway causes self-repair of damaged tubular epithelial cells, but sustained Wnt/ $\beta$-catenin signaling pathway activation results in activation of the renin-angiotensin system (RAS), inflammation, and excessive deposition of extracellular matrix (ECM) $[31,32]$. However, a recent report has proposed a new view whereby activation of Wnt/ $\beta$-catenin signaling pathway induced by short-term IRI in fibroblasts plays a potential role in AKI. In this study, deletion of $\beta$ catenin in fibroblasts increased the expression of HGF in the kidney and reduced the IRI-induced renal damage [18]. HGF secreted by fibroblasts promotes the survival and proliferation of tubule cells and disrupts NF-KB signaling to inhibit inflammation. Thus, HGF plays an important role in the kidney selfrepair after AKI $[33,34]$. These findings promoted us to explore the related mechanism of $\mathrm{Wnt} / \beta$-catenin signaling pathway in fibroblasts in AKI and the potential role of S100A16.

S100A16 belongs to the calcium-binding protein S100 family and is a newly discovered member that is expressed in a variety of tissues. The $\mathrm{S} 100$ family is widely expressed in human tissues and contains of proteins characterized by two EF helix structures with different calcium affinities. The C-terminal EF helix structure consists of a typical $\mathrm{Ca}^{2+}$-binding loop formed by 12 amino acids, while the $\mathrm{N}$-terminal $\mathrm{EF}$ helix structure contains $14 \mathrm{~S} 100$ protein-specific amino acids [35]. The S100 protein are involved in a range of biological processes, and $\mathrm{S} 100$ protein is also associated with multiple diseases, such as inflammation, neurodegenerative diseases, depression, Down's syndrome, cystic fibrosis, and cancers [36]. Multiple members of the S100 family are markers of certain tumors, such as S100A7, S100A13, S100A14 [19, 20]. Notably, according to a recent report, S100A8/A9 could cause cardiomyocytes death in response ischemic/reperfusion injury [37]. Therefore, we speculated that expression of S100 family members may be associated with ischemia injury.

Other reports have indicated that S100 protein can increase Wnt signaling; for example, the role of S100A8 is partially dependent on the activation of Wnt/ $\beta$-catenin signaling, and inhibition of S100A4 expression impedes colon cancer progression caused by the Wnt/ $\beta$-catenin signaling pathway [38, 39]. For these reasons, we anticipated that members of the $S 100$ family would be involved in the activation of Wnt/ $\beta$-catenin signaling. S100A16 is specific in its molecular structure, suggesting that it may have a more complex regulatory mechanism. S100A16 has an EF-helix structure bound to $\mathrm{Ca}^{2+}$ at the $\mathrm{C}$-terminus and $\mathrm{N}$-terminus, whereas the $\mathrm{C}$-terminus is identical to the traditional EF-helix, consisting of 12 highly conserved amino acids. The N-terminal includes the loop consisting of 15 amino acids and it lacks the 
glutamic acid residue at the last position that would normally facilitate the coordination of the calcium binding site. The binding of $\mathrm{Ca}^{2+}$ by S100A16 exposes the hydrophobic binding site to allow binding of the target protein and inductions of various biological functions $[19,40]$. Few reports have been published on the function of S100A16 gene and most studies have focused on its relationship with tumors, cell proliferation and tissue metabolism.

Previous studies have reported high expression of S100A16 in malignant tumors and the promotion of cell invasion and tumor development. However, S100A16 is now viewed as a novel adipogenic factor involved in glycolipid metabolism [41-43], but its functional role in AKI is largely unknown. Here, we have found high expression of S100A16 is highly expressed in the kidney after $24 \mathrm{~h} \mathrm{IRI} \mathrm{surgery} \mathrm{in} \mathrm{mice.}$ S100A16 knockout also relieves the degree of renal injury in vivo and reduces Wnt/ $\beta$-catenin signaling activated by IRI. Based upon single nuclear RNAseq data (http://humphreyslab.com/SingleCell/) done on IRI samples, the gene expression of S100A16 is localized mainly to the macula densa. But our studies here also showed an involvement of the S100A16 found in renal interstitial fibroblasts in the positive regulation of activation of hypoxia-induced Wnt/ $\beta$-catenin signaling pathway. The stability of key molecules, such as $\beta$-catenin and its degradation complex, in the Wnt/ $\beta$-catenin signaling pathway is regulated by the ubiquitin ligase E3 complex, and these ubiquitin ligase complexes are regulated by different signaling molecules in different tissues and cells [44]. The members of $\beta$-catenin degradation complex are significant players in the Wnt/ $\beta$-catenin signaling pathway and are the key molecules that determine the stability and transcriptional activity of $\beta$-catenin. In the absence of Wnt signals, the $\beta$ catenin degradation complex member CK1a first causes phosphorylation of $\beta$-catenin at the Ser 45 site. The $\beta$-catenin is then further phosphorylated at the Thr41, Ser37, and Ser33 sites by the action of GSK3 $\beta$, another member of the $\beta$-catenin degradation complex. The $\beta$-catenin phosphorylated by GSK3 $\beta$ then binds to E3 ubiquitin ligase $\beta$-trcp and is ubiquitinated for proteasome degradation $[45,46]$.

In our previous study, we used protein liquid chromatography-mass spectrometry/mass spectrometry (LC$\mathrm{MS} / \mathrm{MS}$ ) to screen out the $\beta$-catenin degradation complex member CK1a as the one of substrate of the HRD1 E3 ubiquitin ligase [27]. The Ubiquitin-proteasome pathway has essentially three levels: a ubiquitinactivating enzyme (E1), a ubiquitin-conjugating enzyme (E2), and a ubiquitin ligase (E3). Of these, the E3 ubiquitin ligase plays a key role in this ubiquitination process as it determines the specific recognition and binding of ubiquitin molecules and protein substrates [47]. HRD1 is a specific E3 ubiquitin ligase located on the endoplasmic reticulum membrane, where it targets misfolded proteins for degradation in cells, therefore, this ligase is closely related to the development of many diseases [48]. However, the relationship of HRD1 and AKI, and the specific HRD1 substrates that are associated with kidney disease, remains unclear. In our experiments, we found that HRD1 interacted directly with GSK3 $\beta$ and CK1 $a$ and target GSK3 $\beta$ and CK1 a for degradation by proteasome pathway ubiquitination.

Taken together, the findings in this study have provided insights into how the S100A16 activates Wnt/ $\beta$ catenin signaling in AKI. We have identified the S100A16-HRD1-GSK3 $\beta / C K 1 a$ axis as a new Wnt/ $\beta$ catenin signaling mechanism that is active in renal fibroblasts under IRI conditions. The illustration in Fig. 7 shows that GSK3 $\beta$ and CK1a, as members of the $\beta$-catenin degradation complex, interacts with 
HRD1, an E3 ubiquitin ligase, to target proteins for ubiquitination and degradation in conditions of renal injury. $\beta$-catenin is subsequently released and translocated into nucleus in response to $\mathrm{Wnt} / \beta$-catenin signaling activation, and the expression of HGF is repressed, leading to severe kidney damage. The results of this study suggest that the S100A16 is a significant regulator of the Wnt/ $\beta$-catenin signaling activation in fibroblasts when AKI occurs.

\section{Methods And Meterials}

\section{Animal models}

Male C57BL/6J mice (WT) and S100A16 knockout mice (S100A16 ${ }^{+/-}$) (age, 10-12 weeks; body weight, 20-24g) were acquired from the Model Animal Center of Nanjing University (Contract No. [2009] T67). All protocols of the animal experimentation and maintenance comply with the principles of the Institutional Animal Care and Use Committee of Nanjing Medical University.

IRI model experiments were divided into 4 groups ( $n=10$ in each group): sham operation group of wild type (C57BL/6) mice (WT sham), IRI operation group of wild type mice (WT IRI), sham operation group of $\mathrm{S} 100 \mathrm{~A} 16^{+/-}$mice $\left(\mathrm{S} 100 \mathrm{~A} 16^{+/-}\right.$sham), IRI operation group of S100A $16^{+/-}$mice $\left(\mathrm{S} 100 \mathrm{~A} 16^{+/-} \mathrm{IRI}\right)$. The experimental protocol of IRI surgery were as follows: mice were intraperitoneally injected by $1.25 \%$ avertin $(0.1 \mathrm{ml} / 5 \mathrm{~g})$ (Sigma-Aldrich, St Louis, USA) and placed on an electric blanket to maintain body temperature. Bilateral renal pedicles in mice were clamped for 30 minutes using micro-artery clips. Mice were euthanized after renal perfusion of 24 hours, and then serum and kidney tissues were collected respectively. Serum creatinine level and BUN level were measured with automated biochemical analyzer (7600-DDP-ISE; Hitachi Software Engineering, Yokohama, Japan) by Sir run run hospital, Nanjing medical university (Nanjing, China).

\section{Histology and immunohistochemical staining}

The kidney tissues of mice were fixed in $4 \%$ paraformaldehyde for overnight, gradient dehydrated, embedded in paraffin, and then sectioned into slices of about $5 \mu \mathrm{m}$ thickness for HE staining, PAS staining, and IHC staining. The kidney sections were subjected to HE staining and PAS staining by routine protocols to detect renal histopathological changes. For IHC staining, the slices were placed in $0.01 \mathrm{M}$ citrate buffer $\left(\mathrm{pH} \mathrm{6.0)}\right.$ in a pressure cooker $\left(95^{\circ} \mathrm{C}, 2 \mathrm{~min}\right)$ to repair antigens, washed in phosphatebuffered saline (PBS), and then incubated with primary antibody overnight at $4^{\circ} \mathrm{C}$. After 5 minutes $\times 3$ washes with PBS, the sections were incubated with the $\mathrm{IHC}$ secondary antibody at $37^{\circ} \mathrm{C}$ for 30 minutes. The sections were stained by 3,3'-Diaminobenzidine (DAB) reaction, counterstained with hematoxylin, routinely dehydrated, and then sealed with neutral glue. The antibodies against S100A16 (Sigma-Aldrich, St Louis, USA), $\beta$-catenin (BD Biosciences, San Jose, USA), HRD1 (Proteintech, Chicago, USA) were used with 1:100 dilution. All operations were completed in the Sir run run hospital, Nanjing medical university (Nanjing, China).

\section{Cell culture and treatments}


Normal NRK-49F cells were cultured in DMEM/F12 (Gibco, California, USA) containing $10 \%$ fetal bovine serum (BI, Israel) at $37^{\circ} \mathrm{C}$ in $5 \% \mathrm{CO}_{2} / 95 \%$ air. NRK-49F cells were the gifts from Dr. Chunsun Dai (Center for Kidney Diseases, 2nd Affiliated Hospital, Nanjing Medical University). NRK-49F cells were pretreated with different concentrations of Wnt/ $\beta$-catenin signaling pathway small molecule inhibitor ICG-001 (APExBIO, Houston, USA) under hypoxia/reoxygenation. Hypoxia 24 hours and reoxygenation 24 hours in NRK-49F cells were established with Anaeropack (Mitsubishi gas chemical company, Japan).

\section{Transient transfections of plasmids, shRNA and adenovirus}

The constructs of S100A16 OE, pcDNA3.1 (control plasmids of S100A16 OE), S100A16 shRNA, and scrambled shRNA (control S100A16 shRNA), were the gifts of Dr. Yun Liu (The First Affiliated Hospital of Nanjing Medical University) [25]. NRK-49F cells pretreated by ICG-001 were transiently transfected with S100A16 OE or pcDNA3.1 by using lipofectamine 3000 reagent (Invitrogen, CA, USA). Transfection of S100A16 shRNA or scrambled shRNA using lipofectamine 3000 reagent down-regulated the expression of S100A16 in NRK-49F cells, and then NRK-49F cells were collected and subjected to different analyses. HRD1 adenovirus was obtained from Shanghai Genechem Co.

\section{Western blot}

The kidney tissues of mice or treated NRK-49F cells were lysed with radioimmunoprecipitation assay buffer (RIPA buffer) containing $100 \mathrm{mg} / \mathrm{ml}$ phenylmethanesulfonyl fluorid (PMSF), and then subjected to sodium dodecyl sulphate-polyacrylamide gel electrophoresis (SDS-PAGE), transferred to polyvinylidene difluoride (PVDF) membrane, blocked with TBST buffer (1×Tris-buffered saline, $0.1 \%$ Tween20 detergent) containing $5 \%$ nonfat milk for 2 hours at room temperature. Primary antibodies were added to the blots at $4^{\circ} \mathrm{C}$ overnight. The blots were washed with TBST $\times 3$ times for 10 min each time, incubated for 1 hour with horseradish peroxidase-conjugated secondary antibodies in TBST at room temperature, and then washed as described above. The primary antibodies were used as followed: anti-S100A16 and anti-HRD1 were purchased from Proteintech (Chicago, USA), anti-Active $\beta$-catenin, anti-GSK3 $\beta$, anti-BAX, anti-Cleaved caspase3, anti-Caspase3, anti-Ubiquitin, anti-GAPDH, and anti- $\beta$-actin were acquired from Cell Signaling Technology (Danvers, USA), anti- $\beta$-catenin was purchased from BD Biosciences (San Jose, USA), antiCK1a was obtained from Abcam (Cambridge, UK), anti-HGF was purchased from Santa Cruz Biotechnology (Dallas, USA). The band signals were visualized with the enhanced chemi-luminescence (ECL) Plus detection reagent (Thermo Fisher Scientific, Ann Arbor, USA) and imaged with the Image Quant ECL system (PerkinElmer Life Sciences, Wellesley, USA). Image Lab software (Bio-Rad, Hercules, CA, USA) was used to quantified the bands of western blot. The antibody dilution for western blot is 1:1000.

\section{Immunofluorescence staining}

The NRK-49F cells were fixed in $4 \%$ paraformaldehyde solution at $4^{\circ} \mathrm{C}$ overnight, and were blocked by $5 \%$ bull serum albumin (BSA) at $37^{\circ} \mathrm{C}$ for 2 hours. The cell slices were incubated with primary antibody at $37^{\circ} \mathrm{C}$ for 2 hours, and then washed by PBS at room temperature for 3 times $\times 5$ minutes. The sections were incubated with fluorescent secondary antibodies at $37^{\circ} \mathrm{C}$ for 1 hour. After washing with PBS, the cell 
slices were stained by 4'6-diamidino-2-phenylindole (DAPI) for $2 \mathrm{~min}$, and observed with a microscope equipped with a digital camera (IX51 + DP72, OLYMPUS) after washing. The antibodies against S100A16 (Proteintech, Chicago, USA), a-SMA (Sigma-Aldrich, St Louis, USA), $\beta$-catenin (BD Biosciences, San Jose, USA), HRD1 (Proteintech, Chicago, USA), GSK3 $\beta$ (Cell Signaling Technology, Danvers, USA), CK1a (Abcam, Cambridge, UK), were used with 1:100 dilution.

\section{RNA extraction and Real-Time PCR}

The kidney tissues of mice or treated NRK-49F cells were lysed by Trizol reagent according to the manufacturer's instruction (Thermo Fisher Scientific, Ann Arbor, USA). The cDNA was synthesized form RNA by reverse transcription in accordance with the reverse transcription kit system (TOYOBO, Osaka, Japan). PCR was performed by using SYBR Green Master Mix (Applied Biosystems, Foster, USA) and realtime PCR system (Applied Biosystems Step OnePlus ${ }^{\mathrm{TM}}$ ). The mRNA expression of various target genes was normalized to the housekeeping gene $\beta$-actin, and the relative mRNA level compared to the control result was calculated by using the $2^{-\triangle \triangle C T}$ strategy. Primer sequences used for Real-time PCR were showed in supplementary material Table 1.

\section{Co-immunoprecipitation}

The NP40 lysis buffer (50mM Tris, $150 \mathrm{mM} \mathrm{NaCl}, 1 \mathrm{mM}$ EDTA, 0.5\% NP-40, $1 \mathrm{mM}$ PMSF) + PMSF was added to the cells, and then the cells were fully lysed on ice. The corresponding primary antibody was added to cell proteins, and then protein-antibody complex was incubated at $4^{\circ} \mathrm{C}$, 70rpm (revolutions per minute) overnight. The washed protein A/G agarose beads (Thermo Fisher Scientific, Ann Arbor, USA) were added to protein-antibody complex, and then protein-beads complex was incubated at $70 \mathrm{rpm}$ for 6 hours at $4^{\circ} \mathrm{C}$. The complex was washed three times with NP40 lysis buffer, and was added with $2 \times$ SDS loading buffer ( $1 \mathrm{M}$ Tris- $\mathrm{HCl}, 10 \%$ SDS, $50 \%$ glycerin, $0.5 \%$ bromophenol blue, and $5 \% \beta$-mercaptoethanol). After placed at $95^{\circ} \mathrm{C}$ for 10 minutes, the immunoprecipitated proteins were eluted, and then detected by immunoblotting.

\section{Ubiquitylation assays}

HA-Ubiquitin plasmids were transfected with lipofectamine 3000 reagent in NRK-49F cells, and then the cells were transfected by adenovirus HRD1. After transfection for 24 hours, the proteasome inhibitor

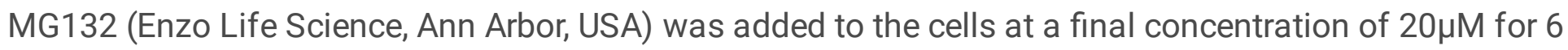
hours. Then cells were lysed in NP40 lysis buffer. The lysates were centrifuged to gain cytoplasmic proteins and incubated with anti-GSK3 $\beta$ antibody or anti-CK1 $\alpha$ antibody overnight, then mixed with protein $\mathrm{A} / \mathrm{G}$ agarose beads at $4^{\circ} \mathrm{C}$ for 6 hours. After washing 3 times with NP40 lysis buffer, the beads released proteins by boiling them in $2 \times$ SDS loading buffer. The released proteins were analyzed by western blot with anti-ubiquitin antibody (Cell Signaling Technology, Danvers, USA) in 1:1000 dilution.

\section{Cycloheximide chase assay}

NRK-49F cells were infected with HRD1 adenovirus to induce HRD1 overexpression. 48 hours later, cycloheximide (Sigma-Aldrich, St Louis, USA) was added at a final concentration of $100 \mu \mathrm{g} / \mathrm{ml}$ (diluted in 
dimethyl sulfoxide) in cells, and then the cell proteins were extracted at different time points after the addition of cycloheximide. SDS- PAGE method as described above.

\section{Statistical analysis}

All data were presented as mean \pm SEM. Statistical analyses of the data were performed using statistical analysis software GraphPad Prism 6.0 (GraphPad Software, Inc. La Jolla, CA, USA). Comparison between groups was made using one-way ANOVA, followed by unpaired $t$ test as appropriate. $P<0.05$ was considered statistically significant.

\section{Declarations}

\section{Ethics approval and consent to participate}

All animal procedures are approved by Institutional Animal Care and Use Committee of Nanjing Medical University. This study does not contain human participants.

\section{Consent for publication}

The authors consent to publication.

\section{Availability of data and material}

All data generated during this study are included in this published article and its supplementary information files.

\section{Competing interests}

The authors have declared that no conflict of interest exists.

\section{Acknowledgements}

We thank Dr. Jie Xu (Center for Advanced Models for Translational Sciences and Therapeutics, University of Michigan) for his critical suggestions and editing of this manuscript.

\section{Funding}

This work was supported by the National Natural Science Foundation of China grants $81870467(\mathrm{XL})$, 81670619 (XL) and 81570779 (DS); Postgraduate Research and Practice Innovation Program of Jiangsu Province grants KYCX19_1119(YS).

\section{Authors' information}

Affiliations: 
Yifei Sun, Zheng Wang and Xiubin Liang

\section{Department of Pathology, Nanjing Medical University, Nanjing 211166, China.}

Ya Fan, Min Li and Dongming Su

Department of Geratology, The First Affiliated Hospital of Nanjing Medical University, Nanjing 210029, China

Yun Liu

Contributions $\rrbracket$

$Y S$ and $X L$ designed all of experiments. YS, YF, ML, ZW and $X L$ conducted the experiments. $Y S, D S, Y L$ and $X L$ participated in the data collection and analysis. YS and XL wrote the manuscript. The authors read and approved the final manuscript.

Corresponding author》

Correspondence to Xiubin Liang.

\section{References}

1. Naqvi R (2021) Epidemiological trends in community acquired acute Kidney Injury in Pakistan: 25 years Experience from a Tertiary Care Renal Unit. Pakistan journal of medical sciences 37:312-319. doi: 10.12669/pjms.37.2.3876

2. Hsu CY (2012) Yes, AKI truly leads to CKD. J Am Soc Nephrol 23:967-9. doi: 10.1681/ASN.2012030222

3. Chawla LS and Kimmel PL (2012) Acute kidney injury and chronic kidney disease: an integrated clinical syndrome. Kidney Int 82:516-24. doi: 10.1038/ki.2012.208

4. Coca SG, Singanamala S and Parikh CR (2012) Chronic kidney disease after acute kidney injury: a systematic review and meta-analysis. Kidney Int 81:442-8. doi: 10.1038/ki.2011.379

5. Chawla LS, Eggers PW, Star RA and Kimmel PL (2014) Acute kidney injury and chronic kidney disease as interconnected syndromes. N Engl J Med 371:58-66. doi: 10.1056/NEJMra1214243

6. Ishani A, Xue JL, Himmelfarb J, Eggers PW, Kimmel PL, Molitoris BA and Collins AJ (2009) Acute kidney injury increases risk of ESRD among elderly. J Am Soc Nephrol 20:223-8. doi: 10.1681/ASN.2007080837

7. Sethi JK and Vidal-Puig A (2010) Wnt signalling and the control of cellular metabolism. Biochem J 427:1-17. doi: 10.1042/BJ20091866 
8. Lim X and Nusse R (2013) Wnt signaling in skin development, homeostasis, and disease. Cold Spring Harb Perspect Biol 5. doi: 10.1101/cshperspect.a008029

9. He W, Dai C, Li Y, Zeng G, Monga SP and Liu Y (2009) Wnt/beta-catenin signaling promotes renal interstitial fibrosis. J Am Soc Nephrol 20:765-76. doi: 10.1681/ASN.2008060566

10. Dai C, Stolz DB, Kiss LP, Monga SP, Holzman LB and Liu Y (2009) Wnt/beta-catenin signaling promotes podocyte dysfunction and albuminuria. J Am Soc Nephrol 20:1997-2008. doi:

10.1681/ASN.2009010019

11. He L, Livingston MJ and Dong Z (2014) Autophagy in acute kidney injury and repair. Nephron Clin Pract 127:56-60. doi: 10.1159/000363677

12. Huang $\mathrm{H}$ and $\mathrm{He} X$ (2008) Wnt/beta-catenin signaling: new (and old) players and new insights. Curr Opin Cell Biol 20:119-25. doi: 10.1016/j.ceb.2008.01.009

13. van Kappel EC and Maurice MM (2017) Molecular regulation and pharmacological targeting of the beta-catenin destruction complex. Br J Pharmacol 174:4575-4588. doi: 10.1111/bph.13922

14. MacDonald BT, Tamai K and He X (2009) Wnt/beta-catenin signaling: components, mechanisms, and diseases. Dev Cell 17:9-26. doi: 10.1016/j.devcel.2009.06.016

15. Hwang I, Seo EY and $\mathrm{Ha} \mathrm{H}$ (2009) Wnt/beta-catenin signaling: a novel target for therapeutic intervention of fibrotic kidney disease. Arch Pharm Res 32:1653-62. doi: 10.1007/s12272-009-2200-3

16. Liu Y (2002) Hepatocyte growth factor and the kidney. Current Opinion in Nephrology and Hypertension 11:23-30. doi: 10.1097/00041552-200201000-00004.

17. Liu Y (2004) Hepatocyte growth factor in kidney fibrosis: therapeutic potential and mechanisms of action. American Journal of Physiology-Renal Physiology 287:F7-F16. doi: 10.1152/ajprenal.00451.2003

18. Zhou D, Fu H, Xiao L, Mo H, Zhuo H, Tian X, Lin L, Xing J and Liu Y (2018) Fibroblast-Specific betaCatenin Signaling Dictates the Outcome of AKI. J Am Soc Nephrol 29:1257-1271. doi:

10.1681/ASN.2017080903

19. Marenholz I and Heizmann CW (2004) S100A16, a ubiquitously expressed EF-hand protein which is up-regulated in tumors. Biochemical and biophysical research communications 313:237-244. doi:

10.1016/j.bbrc.2003.11.115

20. Heizmann CW (2002) S100 proteins structure functions and pathology. Frontiers in Bioscience 7:d1356-1368. doi: 10.2741/a846

21. Yao R, Lopez-Beltran A, Maclennan GT, Montironi R, Eble JN and Cheng L (2007) Expression of S100 Protein Family Members in the Pathogenesis of Bladder Tumors. Anticancer Research 27:3051-3058. 
22. Donato R, Cannon BR, Sorci G, Riuzzi F, Hsu K, Weber DJ and Geczy CL (2013) Functions of S100 proteins. Curr Mol Med 13:24-57.

23. Saito K, Kobayashi M, Nagashio R, Ryuge S, Katono K, Nakashima H, Tsuchiya B, Jiang S-X, Saegusa M, Satoh Y, Masuda N and Sato Y (2015) S100A16 is a Prognostic Marker for Lung Adenocarcinomas. Asian Pacific journal of cancer prevention: APJCP 16:7039-7044. doi: 10.7314/APJCP.2015.16.16.7039

24. Zhu W, Xue Y, Liang C, Zhang R, Zhang Z, Li H, Su D, Liang X, Zhang Y, Huang Q, Liu M, Li L, Li D, Zhao AZ and Liu Y (2016) S100A16 promotes cell proliferation and metastasis via AKT and ERK cell signaling pathways in human prostate cancer. Tumour Biol 37:12241-12250. doi: 10.1007/s13277-016-5096-9

25. Liu Y, Zhang R, Xin J, Sun Y, Li J, Wei D and Zhao AZ (2011) Identification of S100A16 as a Novel Adipogenesis Promoting Factor in 3T3-L1 Cells. Endocrinology 152:903-911. doi: 10.1210/en.2010-1059

26. Sun H, Zhao A, Li M, Dong H, Sun Y, Zhang X, Zhu Q, Bukhari AA, Cao C, Su D, Liu Y and Liang X (2020) Interaction of calcium binding protein S100A16 with myosin-9 promotes cytoskeleton reorganization in renal tubulointerstitial fibrosis. Cell Death Dis 11:146. doi: 10.1038/s41419-020-2337-z

27. Yan C, Xu W, Huang Y, Li M, Shen Y, You H and Liang X (2016) HRD1-Mediated IGF-1R Ubiquitination Contributes to Renal Protection of Resveratrol in db/db Mice. Molecular endocrinology (Baltimore, Md.) 30:600-613. doi: 10.1210/me.2015-1277

28. Ferenbach DA and Bonventre JV (2015) Mechanisms of maladaptive repair after AKI leading to accelerated kidney ageing and CKD. Nature Reviews Nephrology 11:264-276. doi: 10.1038/nrneph.2015.3

29. Wink DA and Mitchell JB (1998) Chemical biology of nitric oxide: insights into regulatory, cytotoxic, and cytoprotective mechanisms of nitric oxide. Free Radical Biology and Medicine 25:434-456. doi: 10.1016/s0891-5849(98)00092-6.

30. Shu S, Wang Y, Zheng M, Liu Z, Cai J, Tang C and Dong Z (2019) Hypoxia and Hypoxia-Inducible Factors in Kidney Injury and Repair. Cells 8:207. doi: 10.3390/cells8030207

31. Zhou D, Tan RJ, Fu H and Liu Y (2016) Wnt/ $\beta$-catenin signaling in kidney injury and repair: a doubleedged sword. Laboratory Investigation 96:156-167. doi: 10.1038/labinvest.2015.153

32. Xiao L, Zhou D, Tan RJ, Fu H, Zhou L, Hou FF and Liu Y (2016) Sustained Activation of Wnt/ $\beta$-Catenin Signaling Drives AKI to CKD Progression. Journal of the American Society of Nephrology 27:1727-1740. doi: 10.1681/asn.2015040449

33. Giannopoulou M, Dai C, Tan X, Wen X, Michalopoulos GK and Liu Y (2008) Hepatocyte Growth Factor Exerts Its Anti-Inflammatory Action by Disrupting Nuclear Factor-kB Signaling. The American Journal of Pathology 173:30-41. doi: 10.2353/ajpath.2008.070583. 
34. Gong R, Rifai A, Ge Y, Chen S and Dworkin LD (2008) Hepatocyte Growth Factor Suppresses Proinflammatory NFKB Activation through GSK3 $\beta$ Inactivation in Renal Tubular Epithelial Cells. Journal of Biological Chemistry 283:7401-7410. doi: 10.1074/jbc.M710396200.

35. Sturchler E, Cox JA, Durussel I, Weibel M and Heizmann CW (2006) S100A16, a Novel Calcium-binding Protein of the EF-hand Superfamily. Journal of Biological Chemistry 281:38905-38917. doi:

10.1074/jbc.M605798200.

36. Cong Y, Cui Y, Wang S, Jiang L, Cao J, Zhu S, Birkin E, Lane J, Ruge F, Jiang WG and Qiao G (2020) Calcium-Binding Protein S100P Promotes Tumor Progression but Enhances Chemosensitivity in Breast Cancer. Frontiers in oncology 10:566302-566302. doi: 10.3389/fonc. 2020.566302

37. Li Y, Chen B, Yang X, Zhang C, Jiao Y, Li P, Liu Y, Li Z, Qiao B, Lau WB, Ma X-I and Du J (2019) S100a8/a9 Signaling Causes Mitochondrial Dysfunction and Cardiomyocyte Death in Response to Ischemic/Reperfusion Injury. Circulation 140:751-764. doi: 10.1161/CIRCULATIONAHA.118.039262

38. van den Bosch MH, Blom AB, Schelbergen RFP, Vogl T, Roth JP, Slöetjes AW, van den Berg WB, van der Kraan PM and van Lent PLEM (2016) Induction of Canonical Wnt Signaling by the Alarmins S100A8/A9 in Murine Knee Joints: Implications for Osteoarthritis. Arthritis \& Rheumatology 68:152-163. doi: 10.1002/art.39420.

39. Dahlmann M, Kobelt D, Walther W, Mudduluru G and Stein U (2016) S100A4 in Cancer Metastasis: Wnt Signaling-Driven Interventions for Metastasis Restriction. Cancers 8:59. doi: $10.3390 /$ cancers8060059.

40. Moravkova P, Kohoutova D, Rejchrt S, Cyrany J and Bures J (2016) Role of S100 Proteins in Colorectal Carcinogenesis. Gastroenterol Res Pract 2016:2632703. doi: 10.1155/2016/2632703

41. Sapkota D, Bruland O, Parajuli H, Osman TA, Teh M-T, Johannessen AC and Costea DE (2015) S100A16 promotes differentiation and contributes to a less aggressive tumor phenotype in oral squamous cell carcinoma. BMC Cancer 15:631. doi: 10.1186/s12885-015-1622-1

42. Tanaka M, Ichikawa-Tomikawa N, Shishito N, Nishiura K, Miura T, Hozumi A, Chiba H, Yoshida S, Ohtake T and Sugino T (2015) Co-expression of S100A14 and S100A16 correlates with a poor prognosis in human breast cancer and promotes cancer cell invasion. BMC Cancer 15:53. doi: 10.1186/s12885-015$1059-6$

43. Li D, Zhang R, Zhu W, Xue Y, Zhang Y, Huang Q, Liu M and Liu Y (2013) S100A16 inhibits osteogenesis but stimulates adipogenesis. Mol Biol Rep 40:3465-73. doi: 10.1007/s11033-012-2413-2

44. Chitalia V, Shivanna S, Martorell J, Meyer R, Edelman E and Rahimi N (2013) c-Cbl, a ubiquitin E3 ligase that targets active $\beta$-catenin: a novel layer of Wnt signaling regulation. The Journal of biological chemistry 288:23505-23517. doi: 10.1074/jbc.M113.473801 
45. Valenta T, Hausmann $G$ and Basler K (2012) The many faces and functions of $\beta$-catenin. The EMBO Journal 31:2714-2736. doi: 10.1038/emboj.2012.150.

46. Wu G, Huang H, Garcia Abreu J and He X (2009) Inhibition of GSK3 phosphorylation of beta-catenin via phosphorylated PPPSPXS motifs of Wnt coreceptor LRP6. PLoS One 4:e4926. doi:

10.1371/journal.pone.0004926

47. Liu W, Tang X, Qi X, Fu X, Ghimire S, Ma R, Li S, Zhang N and Si H (2020) The Ubiquitin Conjugating Enzyme: An Important Ubiquitin Transfer Platform in Ubiquitin-Proteasome System. International journal of molecular sciences 21:2894. doi: 10.3390/ijms21082894

48. Kny M, Standera S, Hartmann-Petersen R, Kloetzel P-M and Seeger M (2011) Herp regulates Hrd1mediated ubiquitylation in a ubiquitin-like domain-dependent manner. The Journal of biological chemistry 286:5151-5156. doi: 10.1074/jbc.M110.134551

\section{Figures}


a
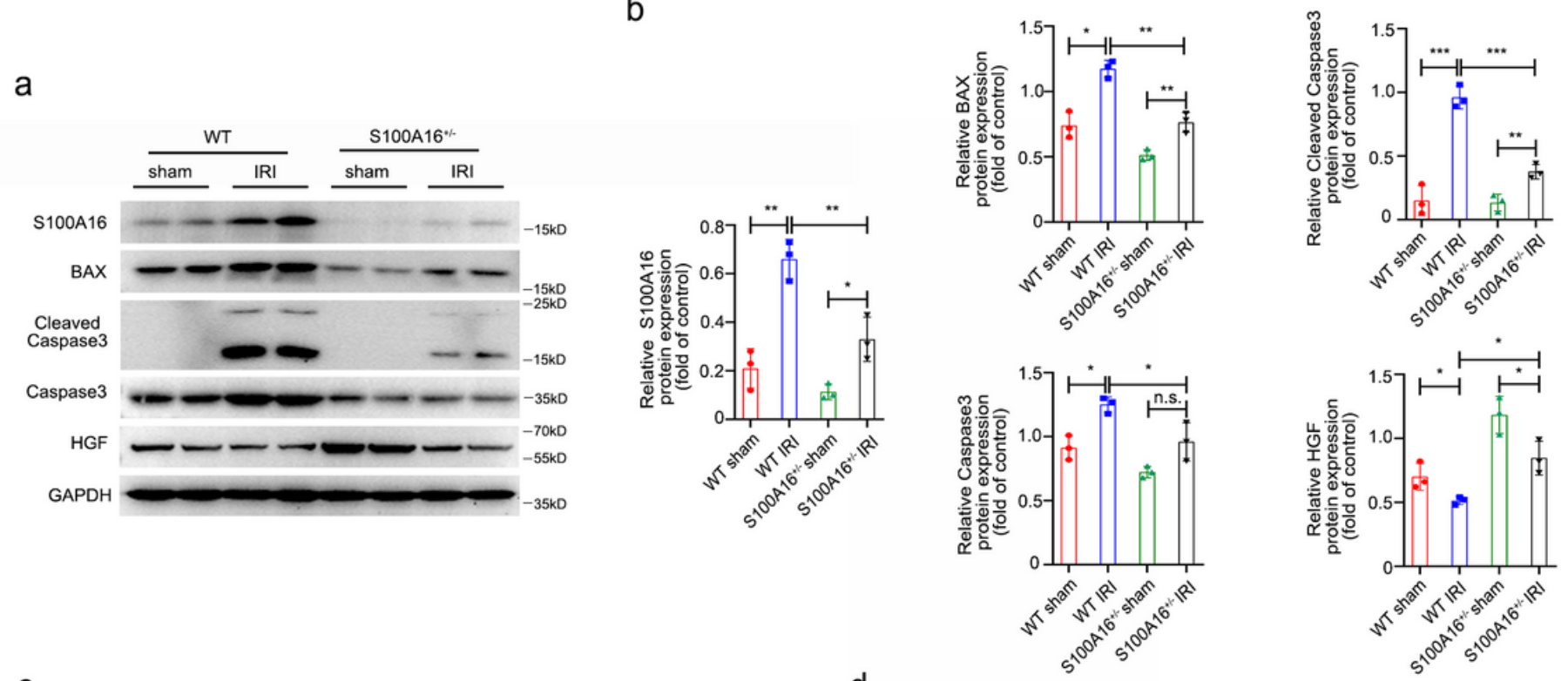

C

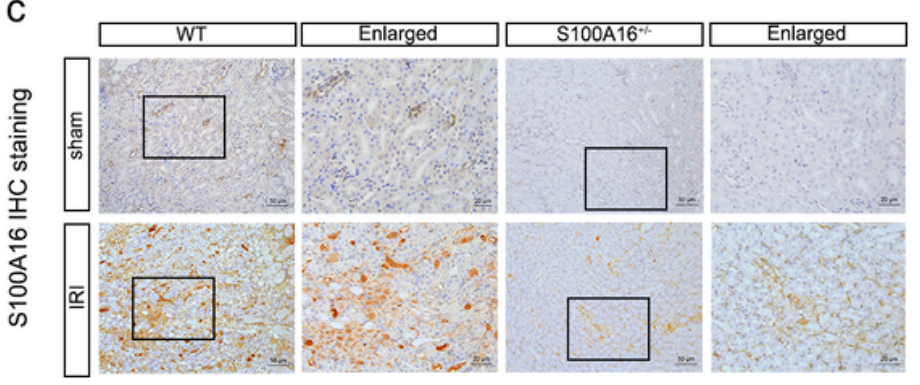

d

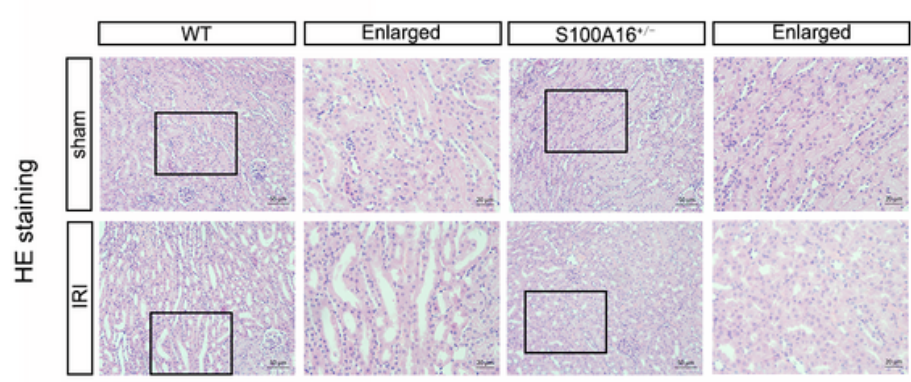

e

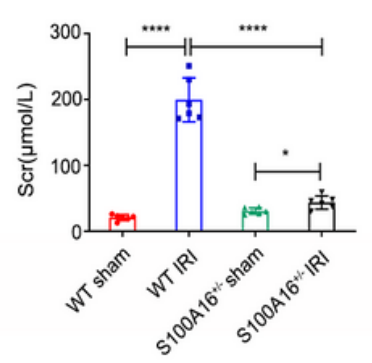

f
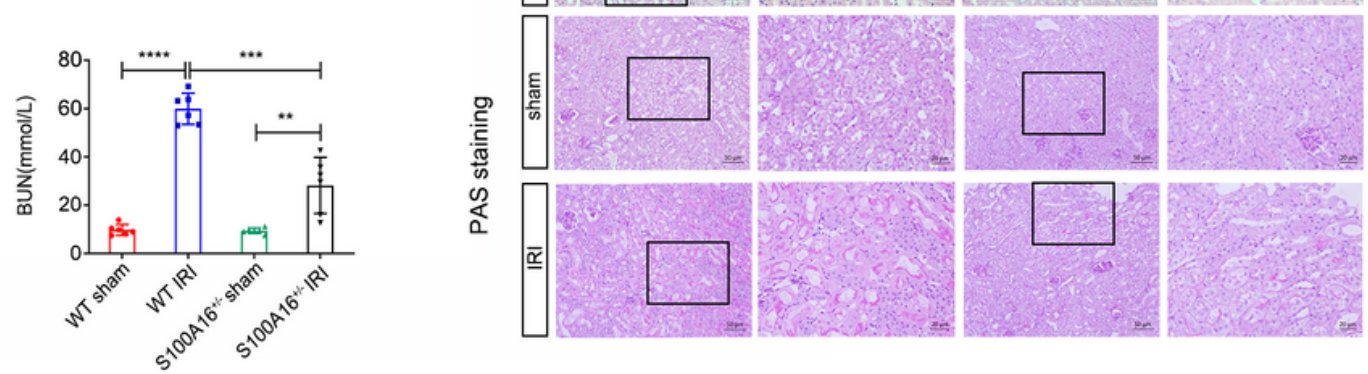

\section{Figure 1}

Knockout of S100A16 in mice reduces kidney injury after AKI. (a) The protein expressions of S100A16, BAX, Cleaved Caspase3, Caspase3 and HGF were tested by western blotting using kidney tissues from WT mice and S100A16+/- mice at 1 day after IRI and compared with tissues from sham mice. (b) Quantitation of immunoblot data for S100A16, BAX, Cleaved Caspase3, Caspase3 and HGF as in panel a. $\star \star \star P<0.001$, ** $P<0.01$, * $P<0.05$, n.s. not significant. (c) Representative micrographs showed renal expression of S100A16 in the WT mice and S100A16+/- mice at 1 day after IRI as determined by

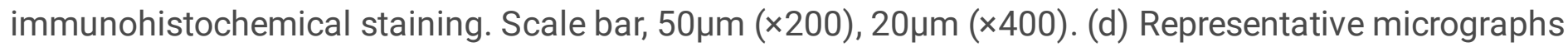
showed morphologic injury in HE and PAS staining sections from the WT mice and S100A16+/- mice at 1 day after IRI. Scale bar, 50 $\mathrm{m}(\times 200), 20 \mu \mathrm{m}(\times 400)$. (e) Scr level in the WT mice and S100A16+/- mice at 1 day after IRI, compared with sham mice. $\star \star \star \star ~ P<0.0001, * P<0.05$, versus sham mice. (f) BUN in the WT 
mice and S100A16+/- mice at 1 day after IRI, compared with sham mice. $* \star \star \star ~ P<0.0001, * \star \star P<0.001$, $* \star$ $P<0.01$, versus sham mice.
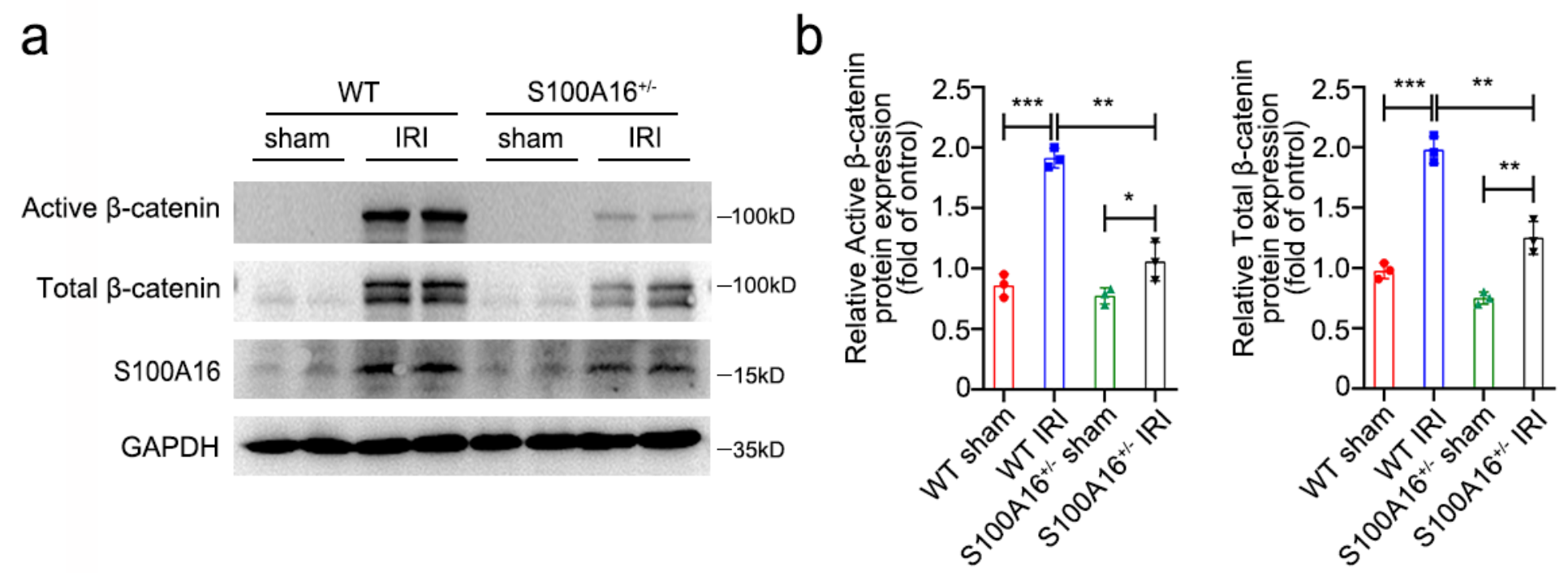

C
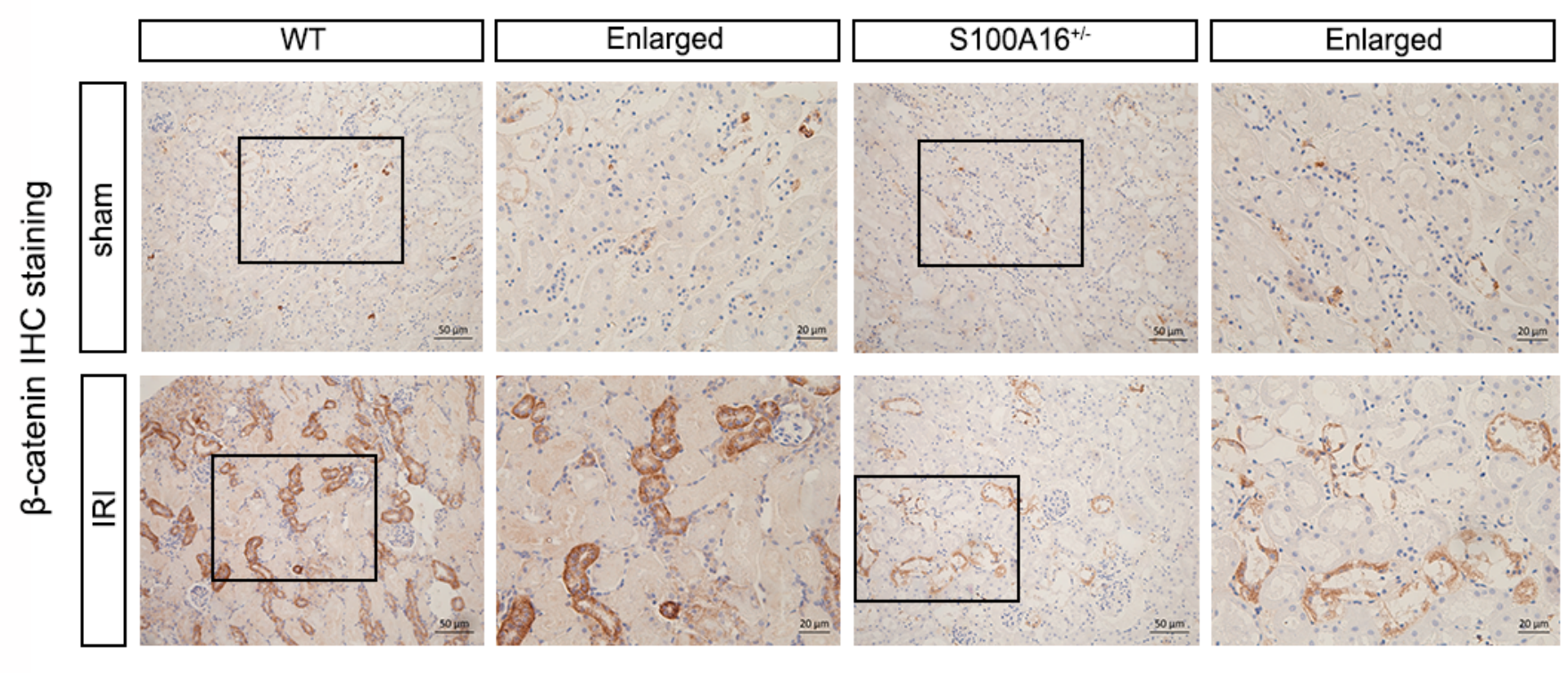

\section{Figure 2}

S100A16 knockout in mice disrupts Wnt/ $\beta$-catenin pathway activation after AKI. (a) The expressions of Active $\beta$-catenin, Total $\beta$-catenin, and S100A16 were detected by western blotting using kidney tissues from WT mice and S100A16+/- mice at 1 day after IRI, and sham mice were used as control. (b) Quantitation of western blot data for Active $\beta$-catenin and Total $\beta$-catenin proteins as in panel a. $* \star \star$ $P<0.001$, ** $P<0.01$, * $P<0.05$. (c) Representative micrographs showed renal expression of $\beta$-catenin in the WT mice and S100A16+/- mice at 1 day after IRI as determined by immunohistochemical staining. Scale bar, $50 \mu \mathrm{m}$ (×200), $20 \mu \mathrm{m}(\times 400)$. 
a

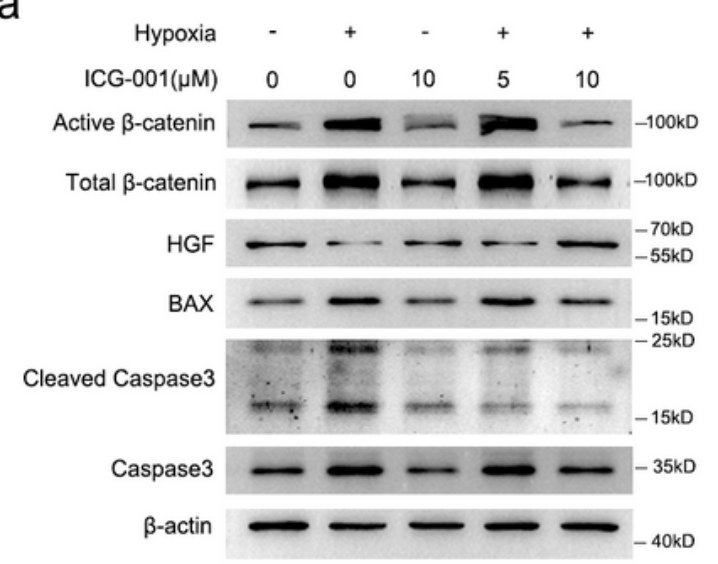

C

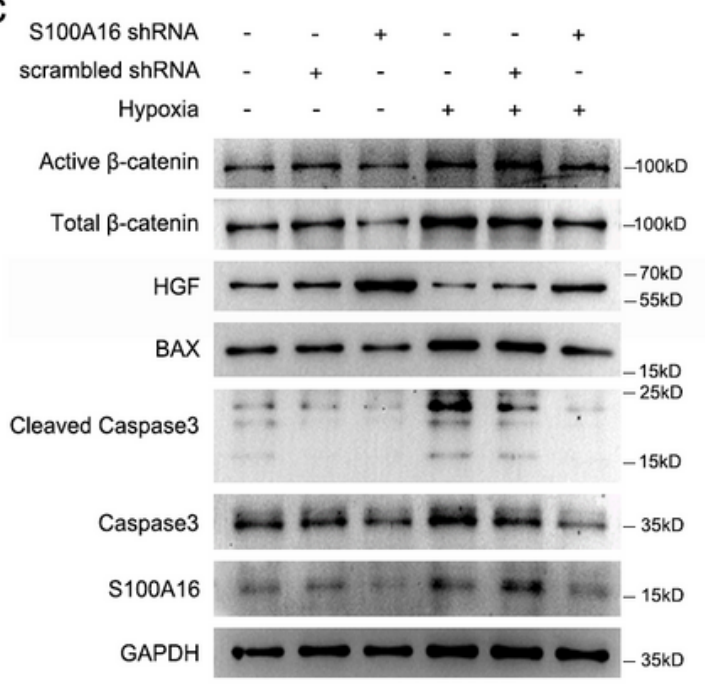

e

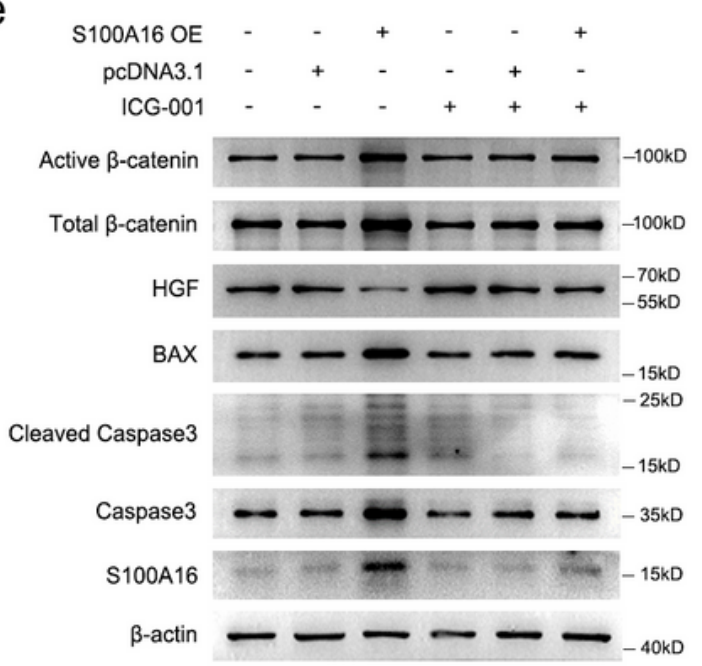

b
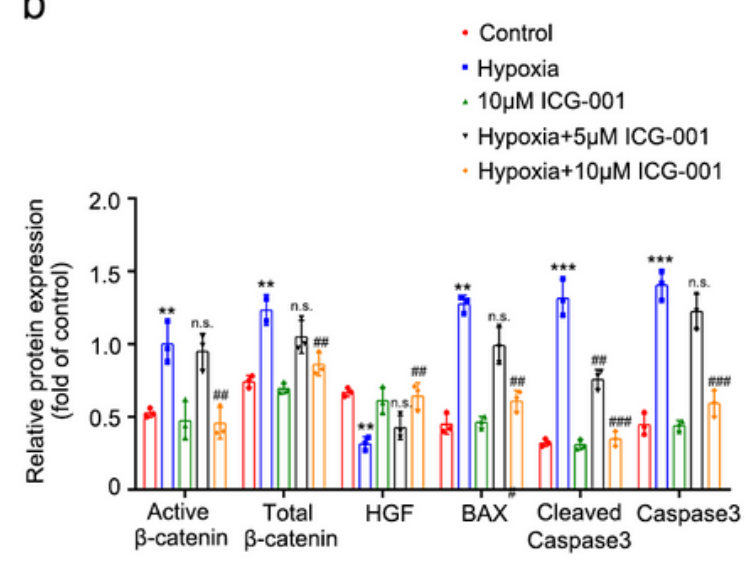

d

- scrambled shRNA

- S100A16 shRNA

- Hypoxia+scrambled shRNA

- Hypoxia+S100A16 shRNA

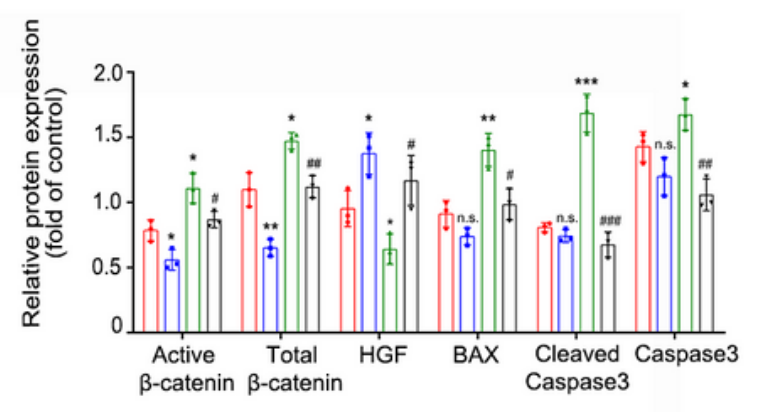

f

- pcDNA3.1

- S100A16 OE

- pcDNA3.1+ICG-001

- S100A16 OE+ICG-001

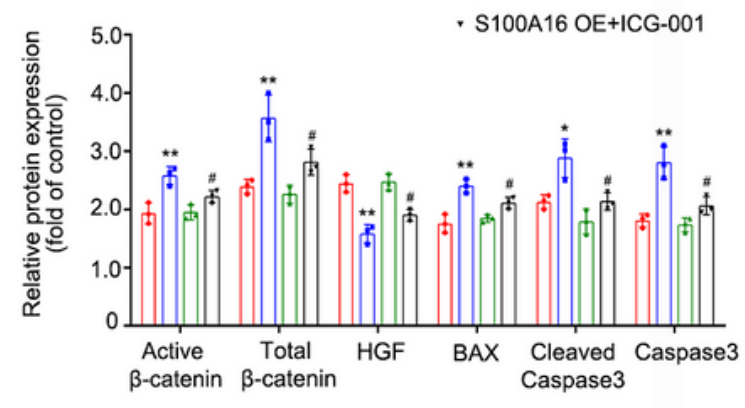

\section{Figure 3}

Wnt/ $\beta$-catenin pathway activation is affected by regulating S100A16 in hypoxia-induced NRK-49F cells. (a) Western blot analyses showed that ICG-001 blocked Wnt/ $\beta$-catenin pathway activation induced by hypoxia in NRK-49F cells. Cell lysates after ICG-001 treatment as indicated were immunoblotted with antibodies against Active $\beta$-catenin, Total $\beta$-catenin, HGF, BAX, Cleaved Caspase3, Caspase 3 and $\beta$-actin. (b) Quantitation of western blot data for Active $\beta$-catenin, Total $\beta$-catenin, HGF, BAX, Cleaved Caspase3 
and Caspase3 proteins as in panel a. ${ }^{\star \star \star} P<0.001$, ${ }^{\star *} P<0.01$, versus control; \#\#\# $P<0.001$, \#\# $P<0.01$, n.s. not significant, versus hypoxia alone. (c) Western blot analyses showed that knockdown S100A16 inhibited hypoxia-induced the increased expressions of Active $\beta$-catenin, Total $\beta$-catenin, BAX, Cleaved Caspase3, and Caspase3 in NRK-49F cells. Knockdown S100A16 also recovered the HGF expression. (d) Quantitation of western blot data for Active $\beta$-catenin, Total $\beta$-catenin, HGF, BAX, Cleaved Caspase3, and Caspase3 proteins as in panel c. ${ }^{\star * \star} P<0.001,{ }^{\star} * P<0.01,{ }^{*} P<0.05$, n.s. not significant, versus scrambled shRNA; \#\#\# $\mathrm{P}<0.001$, \#\# $\mathrm{P}<0.01$, \# $\mathrm{P}<0.05$, versus hypoxia+ scrambled shRNA. (e) Western blot analyses displayed the elevated protein expressions of Active $\beta$-catenin, Total $\beta$-catenin, BAX, Cleaved Caspase3, and Caspase3 in S100A16 overexpressing NRK-49F cells, and these genes could be impeded by ICG-001. By contrast, the decreased HGF expression caused by S100A16 overexpression could be recovered by ICG-001. (f) Quantified Active $\beta$-catenin, Total $\beta$-catenin, HGF, BAX, Cleaved Caspase3, and Caspase3 protein levels in panel e. ** $\mathrm{P}<0.01$, ${ }^{*} \mathrm{P}<0.05$, versus pcDNA3.1; \# $\mathrm{P}<0.05$, versus S100A16 OE.

a

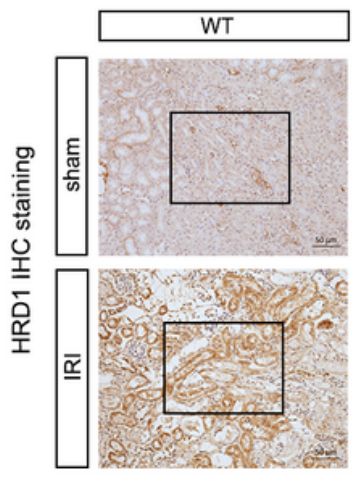

b

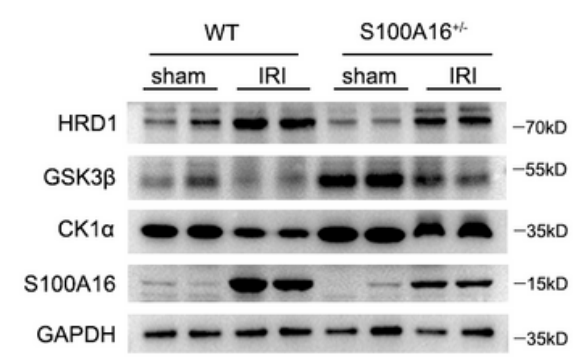

d

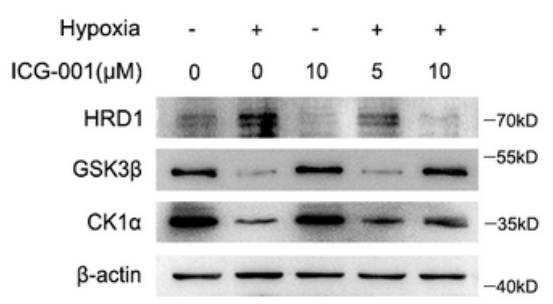
Enlarged
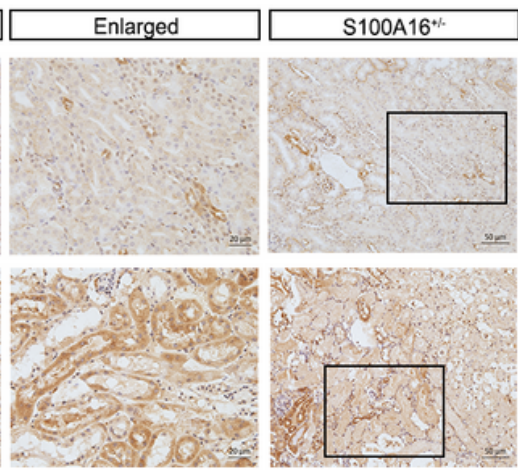

C

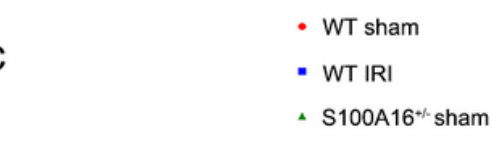

- S100A16*/. IRI

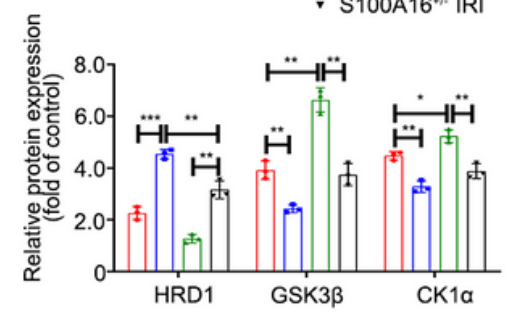

e

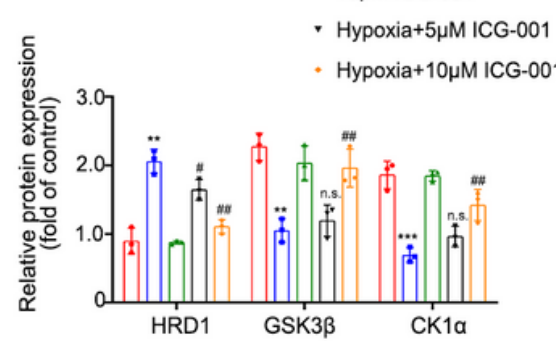

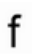

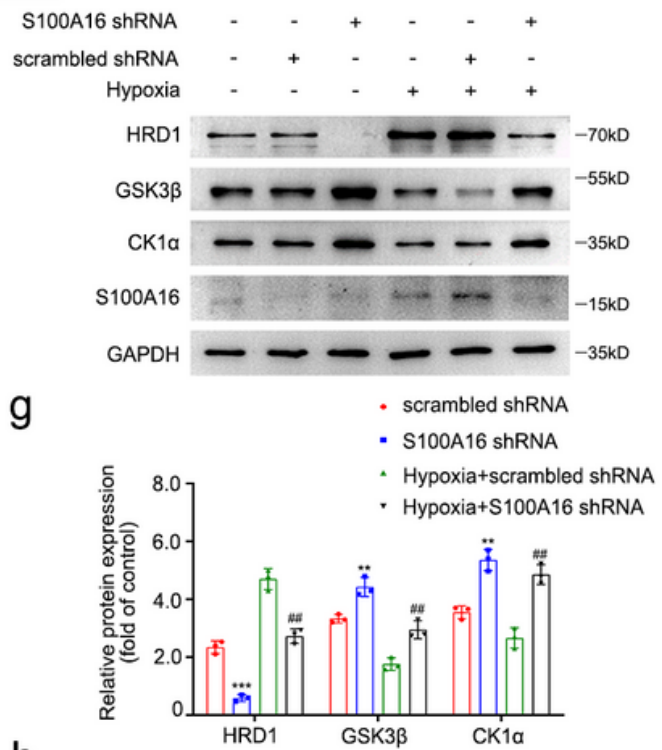

h

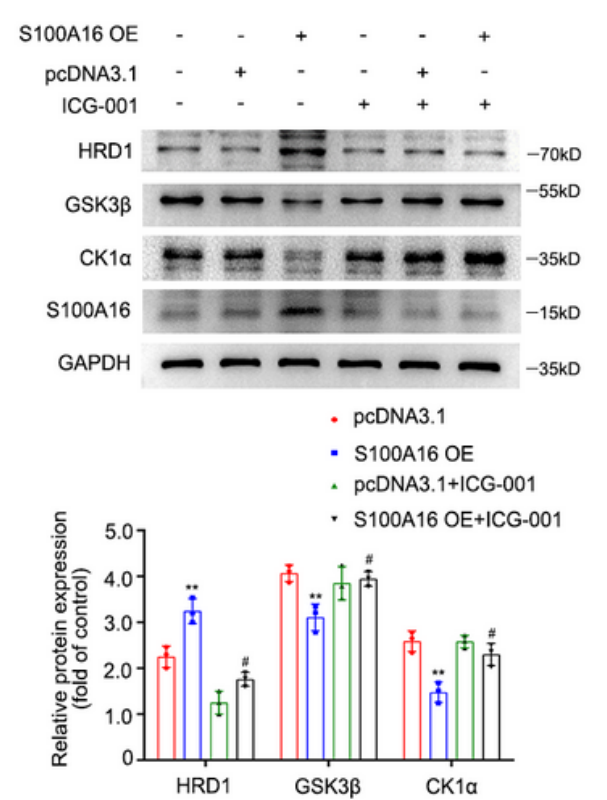




\section{Figure 4}

HRD1 involved in the activation of Wnt/ $\beta$-catenin signaling pathway and is regulated by S100A16 in injured renal fibroblasts. (a) Representative micrographs showed the renal expression of HRD1 in the WT mice and S100A16+/- mice at 1 day after IRI, as determined by immunohistochemical staining. Scale bar, $50 \mu \mathrm{m}(\times 200), 20 \mu \mathrm{m}(\times 400)$. (b) HRD1, GSK3 $\beta$ and CK1 a expressions were tested using kidney tissues from WT mice and S100A16+/- mice at 1 day after IRI compared with sham mice by western blot assays.

(c) Quantitation of immunoblot data for HRD1, GSK3 $\beta$ and CK1 a proteins as in panel b. ${ }^{\star \star *} P<0.001$, ** $P<0.01$, * $P<0.05$. (d) Western blot analyses show that ICG-001 blocked the increased HRD1 expression induced by hypoxia in NRK-49F cells, and ICG-001 also recovered the expressions of GSK3 $\beta$ and CK1a. Cell lysates after various treatments, as indicated, were immunoblotted with antibodies against HRD1, GSK3 $\beta$ and CK1 $a$ and $\beta$-actin. (e) Quantitation of western blot data for HRD1, GSK3 $\beta$ and CK1a proteins as in panel d. $\star \star \star ~ P<0.001$, $* * P<0.01$, versus control; \#\# $P<0.01$, \# $P<0.05$, n.s. not significant, versus hypoxia alone. (f) Western blot analyses showed that knockdown of S100A16 inhibited the HRD1 expression and enhanced the expressions of GSK3 $\beta$ and CK1 $1 \mathrm{a}$ in normal or hypoxia conditions. $(\mathrm{g})$ Quantitation of western blot data for HRD1, GSK3 $\beta$ and CK1a proteins as in panel f. *** $P<0.001$, ** $P<0.01$, versus scrambled shRNA; \#\# $P<0.01$, versus hypoxia+ scrambled shRNA. (h) Western blots showed that overexpression of S100A16 increased the HRD1 expression, but it was impeded by ICG-001 in NRK-49F cells. The GSK3 $\beta$ and CK1 $a$ expressions were opposite to HRD1. (i) Quantified HRD1, GSK3 $\beta$ and CK1a protein levels in panel $h .{ }^{* *} \mathrm{P}<0.01$, versus pcDNA3.1; \# $\mathrm{P}<0.05$, versus S100A16 OE. 


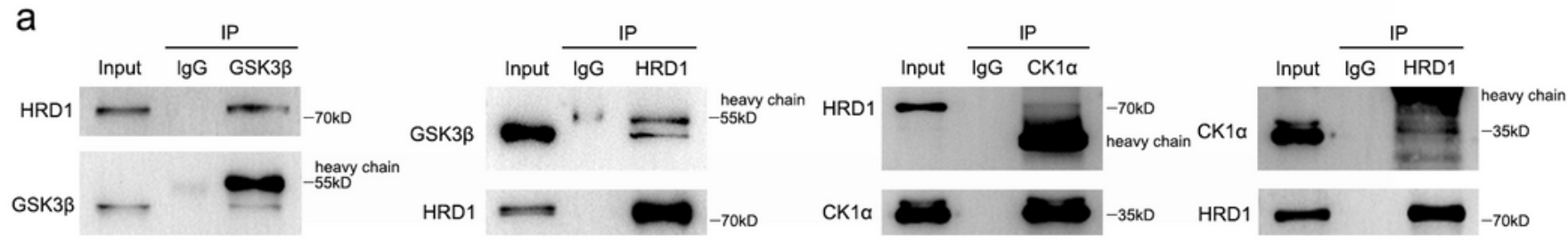

b

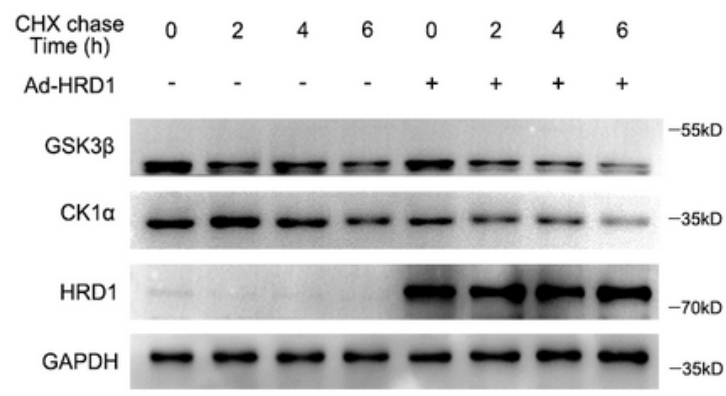

d

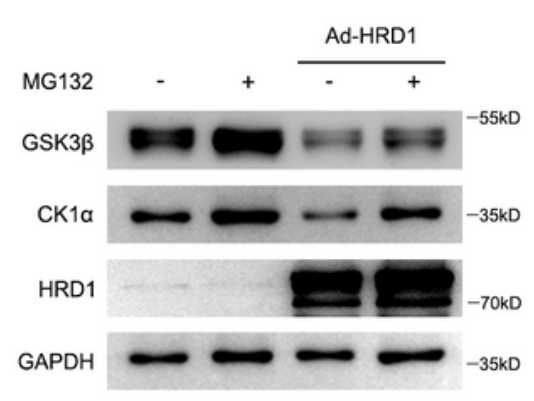

f

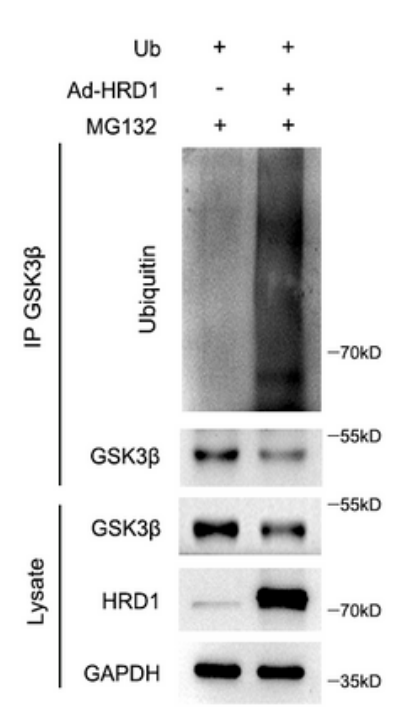

g
C
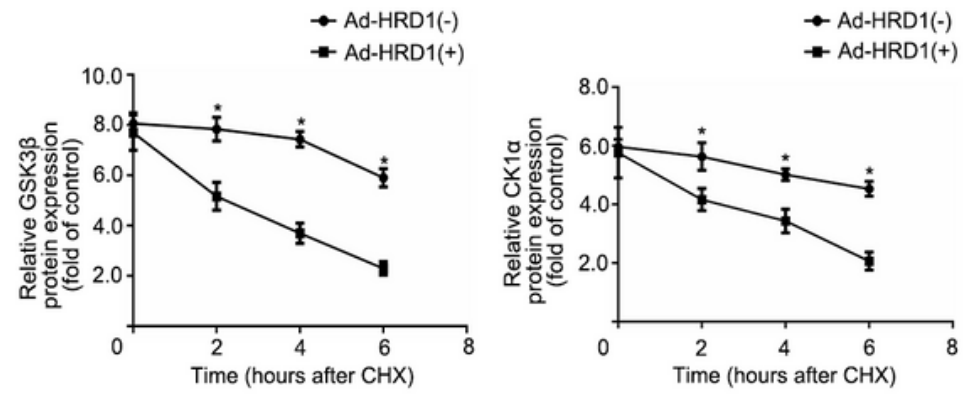

e
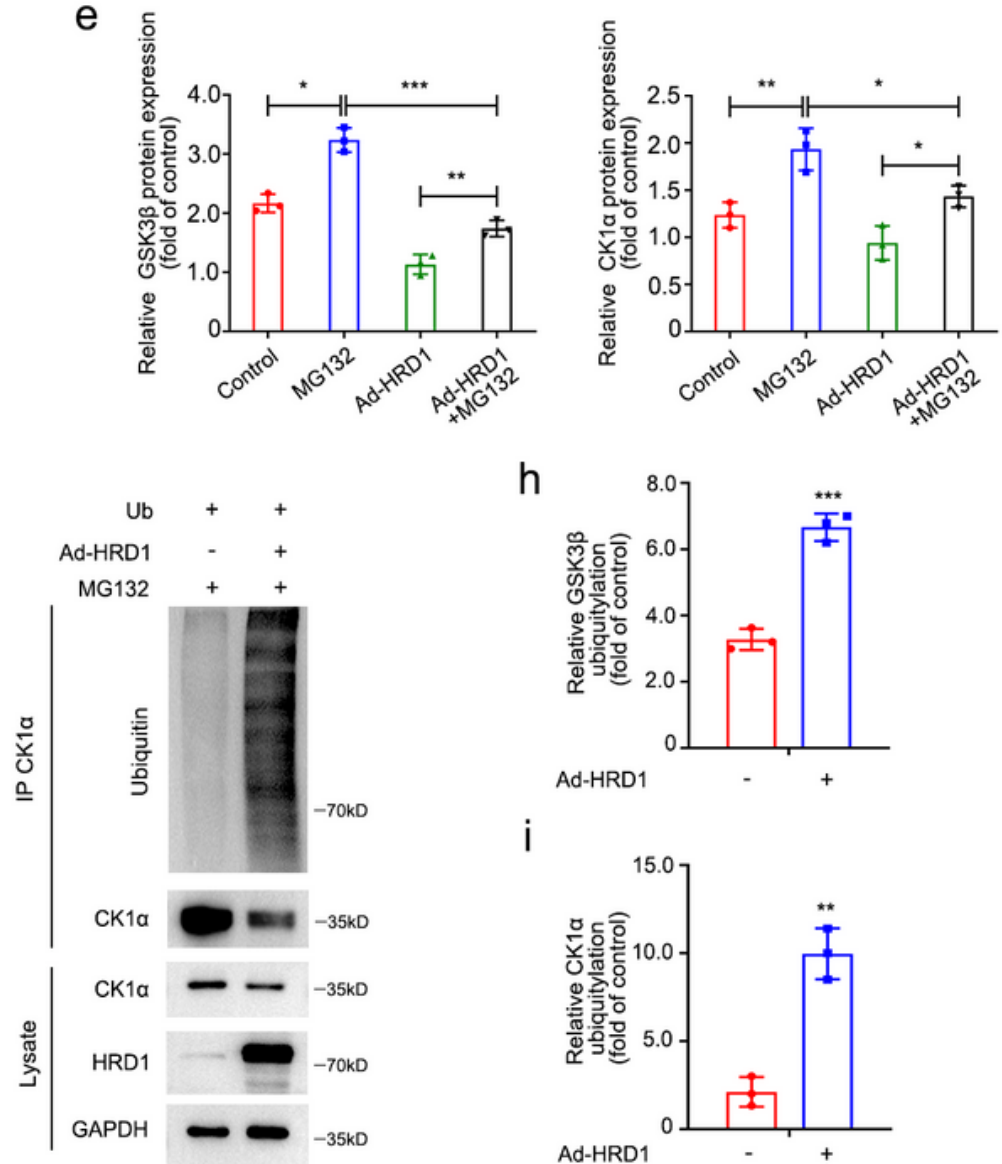

$\mathrm{h}$
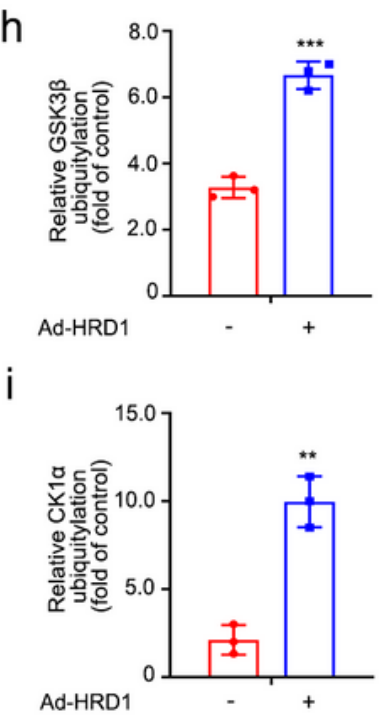

\section{Figure 5}

HRD1 degrades GSK3 $\beta$ and CK1a via the ubiquitin-proteasome pathway in NRK-49F cells. (a) The interaction between HRD1 and either GSK3 $\beta$ or CK1 $a$ was detected in the co-IP analysis in NRK-49F cells. (b) A cycloheximide chase was performed to establish the time course of GSK3 $\beta$ and CK1a biogenesis. NRK-49F cells were infected with or without Ad-HRD1 for $48 \mathrm{~h}$, and then the cells were treated with $\mathrm{CHX}$ $(100 \mu \mathrm{g} / \mathrm{ml})$ for $0,2,4$ or $6 \mathrm{~h}$. The expressions of GSK3 $\beta$ and CK1 $\mathrm{a}$ in whole-cell lysates were measured by 
western blotting. (c) Quantitation of western blot data for GSK3 $\beta$ and CK1a proteins as in panel b. * $P<0.05$. (d) The presence of MG132 $(20 \mu \mathrm{M})$ increased the expressions of GSK3 $\beta$ and CK1 $a$ with or without Ad-HRD1 infection compared with controls in NRK-49F cells. (e) Quantification of GSK3 $\beta$ and CK1 a protein expressions from experiments as shown in panel $d$. ${ }^{* *} P<0.001$, ${ }^{*} P<0.01, * P<0.05$. (f) More ubiquitin conjugated to GSK3 $\beta$ was detected in the cells overexpressing HRD1 compared with no HRD1 transfection. $(\mathrm{g})$ More ubiquitin conjugated to CK1 a was detected in the cells overexpressing HRD1 compared with no HRD1 transfection. (h) Quantification of ubiquitin conjugated to GSK3 $\beta$ as in panel $f$, normalized to GAPDH expression. ${ }^{\star \star \star} P<0.001$. (i) Quantification of ubiquitin conjugated to $C K 1 \mathrm{a}$ as in panel $g$, normalized to GAPDH expression. ${ }^{* *} \mathrm{P}<0.01$. 
a

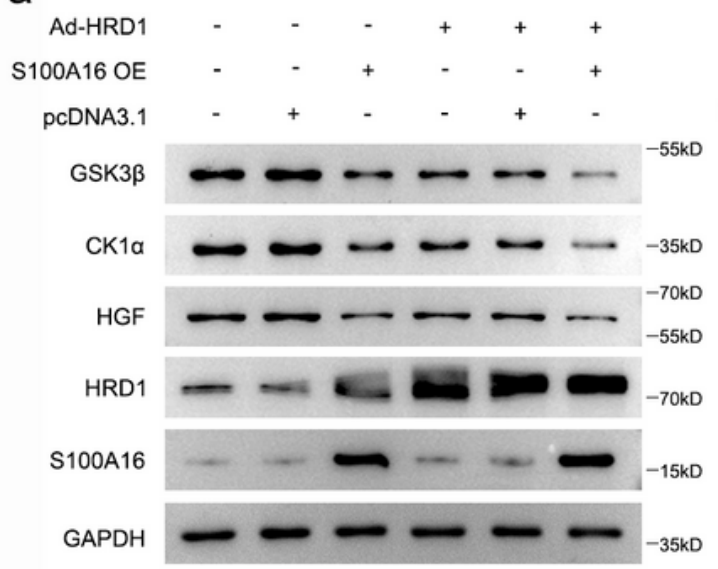

b

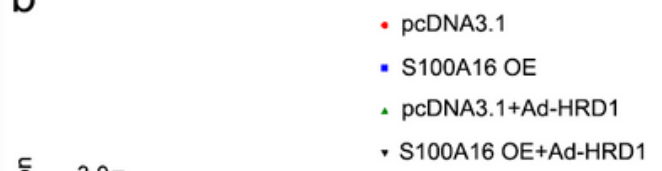

d

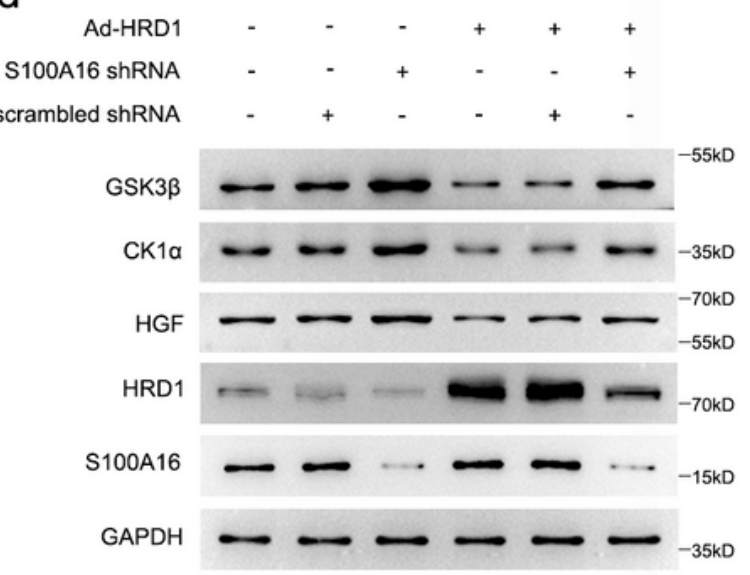

e

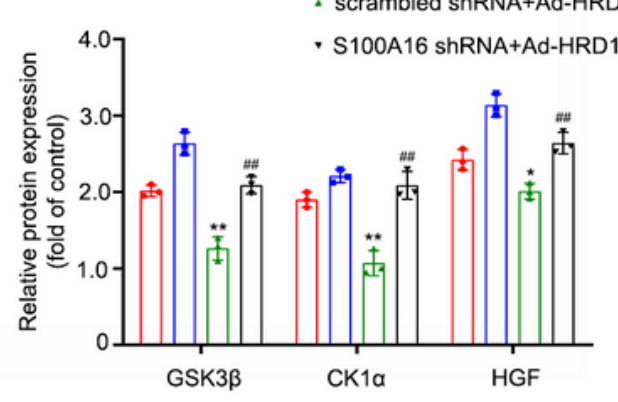

- S100A16 ShRNA

- scrambled shRNA+Ad-HRD1

- S100A16 shRNA+Ad-HRD1

f

DAPI

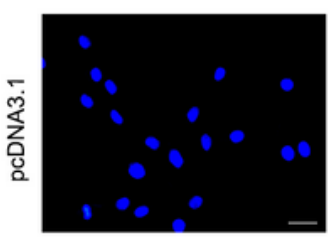

$\beta$-catenin
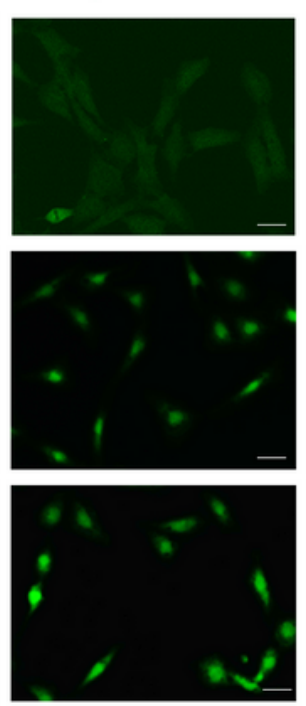

Merge
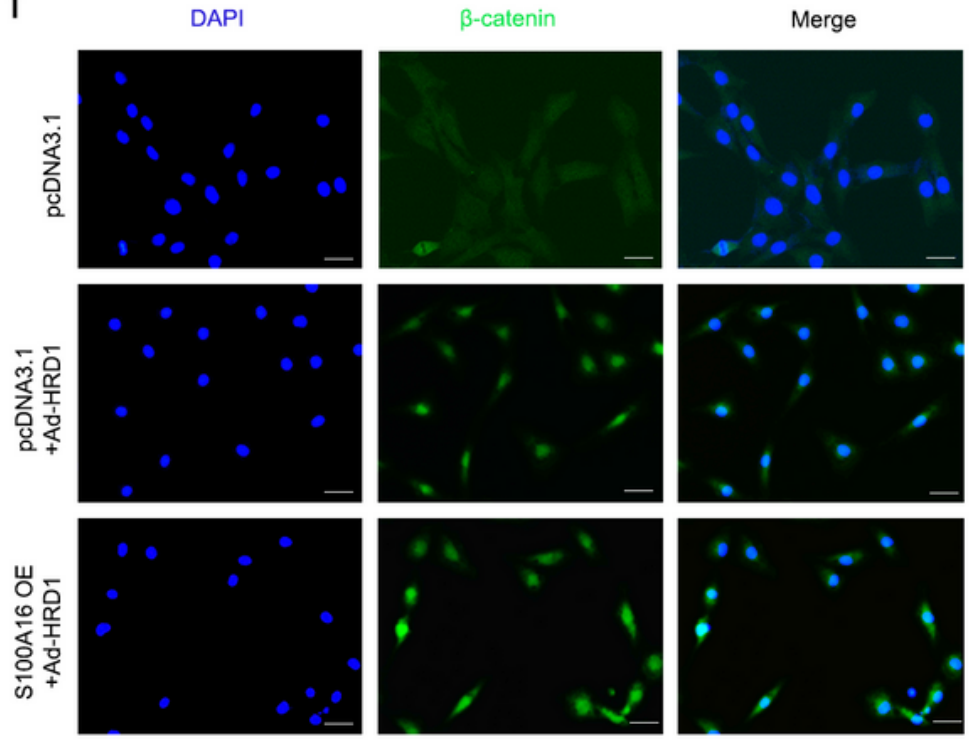

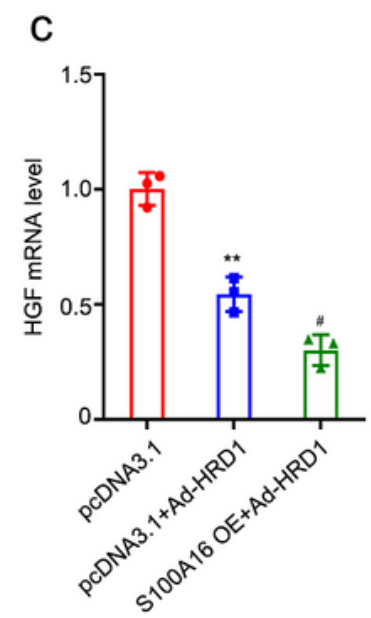

\section{Figure 6}

S100A16 down-regulates the expressions of GSK3 $\beta$ and CK1 a by HRD1 to affect downstream HGF in NRK-49F cells. (a) Western blot analyses showed that overexpression of S100A16 aggravated the downregulated expressions of GSK3 $\beta$, CK1 $a$, and HGF induced by Ad-HRD1 in NRK-49F cells. (b) Quantitation of western blot data for GSK3 $\beta$, CK1 $a$, and HGF proteins, as in panel a. ${ }^{*} P<0.05$, versus pcDNA3.1; \#\# P<0.01, versus pcDNA3.1+Ad-HRD1. (c) Real-time qPCR demonstrated that overexpression 
of S100A16 aggravated the reduction of HGF mRNA level induced by Ad-HRD1 compared with the AdHRD1 treatment alone in NRK-49F cells. ${ }^{*} \mathrm{P}<0.01$, versus pcDNA3.1; \# $\mathrm{P}<0.05$, versus pcDNA3.1+AdHRD1. (d) Western blot analyses showed that knockdown S100A16 recovered Ad-HRD1-induced the down-regulated expressions of GSK3 $\beta$, CK1a, and HGF. (e) Quantitation of western blot data for GSK3 $\beta$, CK1a and HGF proteins, as in panel $d .{ }^{*} P<0.05$, ${ }^{\star *} P<0.01$ versus scrambled shRNA; \#\# $P<0.01$, versus scrambled shRNA+Ad-HRD1. (f) Representative images showed the accumulation of $\beta$-catenin fluorescence in the nucleus of HRD1-overexpressing NRK-49F cells. The $\beta$-catenin fluorescence was amplified after overexpressing S100A16 in the HRD1-overexpressing NRK-49F cells. Scale bar, 20um.

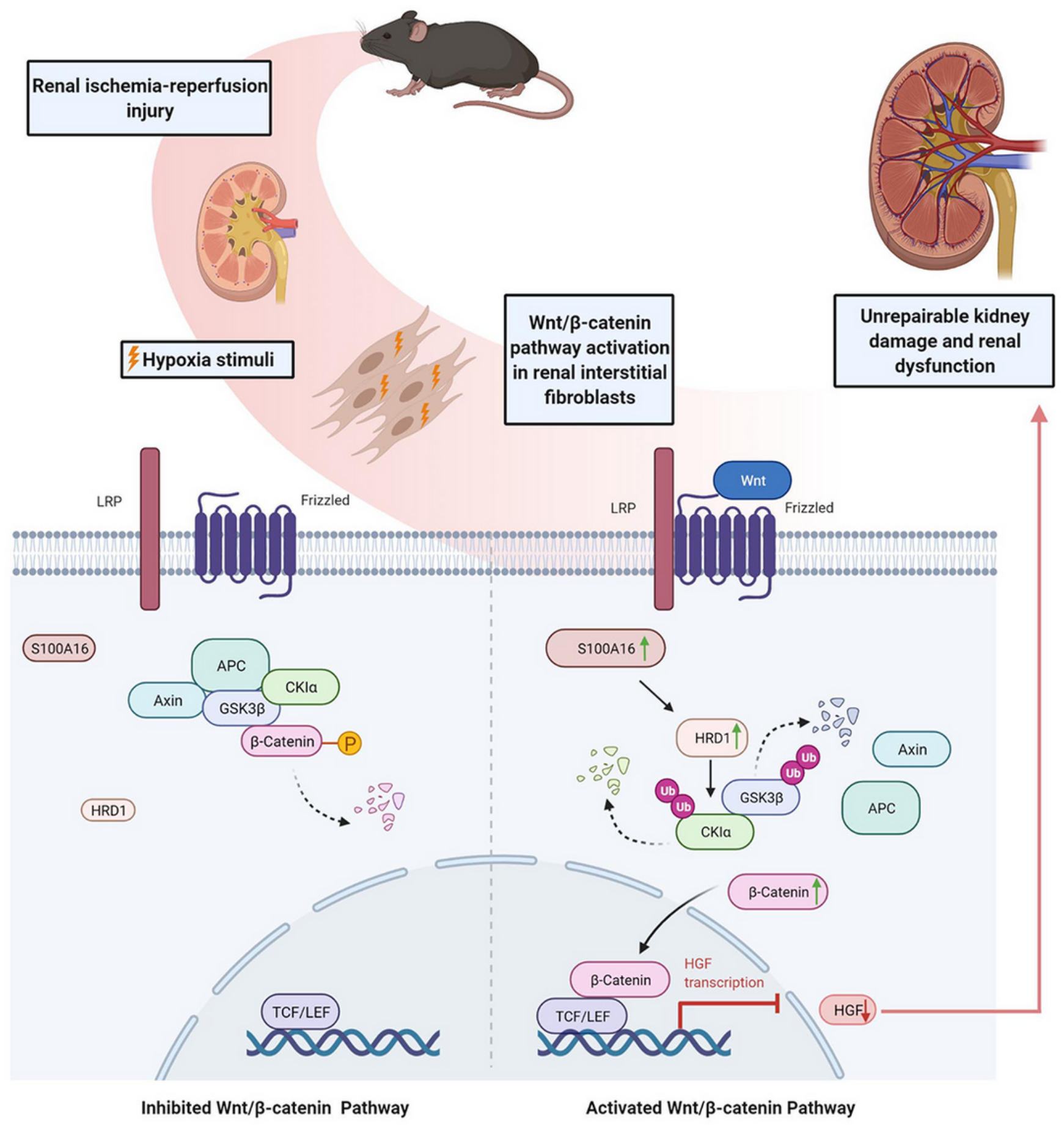




\section{Figure 7}

The Wnt/ $\beta$-catenin signaling activation induced by S100A16-HRD1-GSK3 $\beta / C K 1$ a pathway in renal fibroblasts under IRI conditions promotes the occurrence of AKI. Schematic diagram shows the increased expression of S100A16 in fibroblasts during renal ischemia and hypoxia. The expression of the E3 ubiquitin ligase HRD1 is elevated, and the members of $\beta$-catenin degradation complex, GSK3 $\beta$ and CK1a, are destroyed via the ubiquitin-proteasome pathway, thereby promoting accumulation of $\beta$-catenin and its transfer to the cell nucleus. Activation of the Wnt/ $\beta$-catenin signaling pathway then inhibits the transcription of the downstream HGF that secreted by fibroblasts, and this eventually leads to the unrepairable kidney injury and renal dysfunction.

\section{Supplementary Files}

This is a list of supplementary files associated with this preprint. Click to download.

- SupplementarymaterialsS100A16AKICMLS.pdf 